\title{
Scofflaw bicycling: Illegal but rational
}

\author{
Wesley E. Marshall \\ University of Colorado Denver \\ wesley.marshall@ucdenver.edu
}

\author{
Daniel Piatkowski \\ University of Nebraska-Lincoln \\ dpiatkowski2@unl.edu
}

\section{Aaron Johnson}

\section{University of Colorado Boulder aaron.johnson@colorado.edu}

Abstract: Nearly everyone has jaywalked, rolled through a stop sign, or driven a few miles per hour over the speed limit, but most such offenses face no legal consequences. Society also tends to see these relatively minor infractions that almost all people make-though they are unmistakably illegal_-as normal and even rational. Bicyclists who break the law, however, seem to attract a higher level of scorn and scrutiny. While the academic literature has exhaustively covered unlawful driving behaviors, there remains little research on bicyclists who break the rules of the road. This paper examines rule-breaking bicyclists and the factors associated with such behaviors. We also explore the question: are bicyclists making rational, albeit illegal, choices-similar to most drivers and pedestrians-or are bicyclists reckless and dangerous? Because it's proven effective for reaching hard-to-reach populations, we employed a snowball-sampling framework and an online, scenario-based survey completed by nearly 18,000 respondents. Via multi-level statistical analyses, our results suggest that younger people and males tend to exhibit higher levels of illegal bicycling behavior, but even when combining high-risk factors, the overwhelming majority of bicyclists are not reckless. Controlling for the context and social norms of the city where one lives tends to outweigh individual bicyclist characteristics such as race/ethnicity and income. Unlawful drivers and pedestrians tend to rationalize their behaviors as time saving; bicyclists similarly rationalize their illegal behaviors but were more inclined to cite increasing their own personal safety and/or saving energy. Most bicyclists can generally be described as rational individuals trying to function safely and efficiently given the context and norms of where they live and the transportation system put in front of them.

\section{Article history:}

Received: January 8, 2016

Received in revised form: June

9, 2016

Accepted: August 10, 2016

Available online: March 8, 2017

Copyright 2017 Wesley E. Marshall, Daniel Piatkowski \& Aaron Johnson http://dx.doi.org/10.5198/jtlu.2017.871

ISSN: 1938-7849 | Licensed under the Creative Commons Attribution - Noncommercial License 3.0

The Journal of Transport and Land Use is the official journal of the World Society for Transport and Land Use (WSTLUR) and is published and sponsored by the University of Minnesota Center for Transportation Studies. This paper is also published with additional sponsorship from WSTLUR. 


\section{Introduction}

When it comes to our transportation system, everybody is a criminal. Almost all road users have jaywalked, rolled slowly through a stop sign, taken an illegal right turn on red, or driven a few miles-perhour over the speed limit. While you might get a citation for doing one of these things, the overwhelming majority of such offenses face little in terms of legal consequences (Davis, 1997; Rinella, 1967; Engel \& Calnon, 2004; McLean \& Rojek, 2016). More broadly, society also tends to react with general indifference (Corbett \& Simon, 1992). Society certainly does not deem those that perpetrate seemingly minor traffic crimes as criminals, in part because doing so would effectively label us all criminals (Becker, 1974). When it comes to breaking the law in the transportation system, we tend to perceive these relatively minor infractions — even though they are clearly illegal—as rational choices with little risk that almost all of us make given the transportation system put in front of us.

In contrast to the inattention shown to the minor infractions of drivers and pedestrians, bicyclists appear to be disproportionately demonized. Popular press portrays bicyclists as reckless and a pervasive problem with potentially dire consequences (Goodyear, 2013; O’Rourke, 2011; Milloy, 2014). Whether unlawful bicyclists are also reckless is something that we will explore in this paper. Either way, the research suggests that a red-light-running bicyclist angers drivers more than any other road user behavior (O'Brien, Tay, and Watson, 2002; Kidder, 2005; Fincham, 2006). While the academic literature has exhaustively covered driving behaviors, there remains little research on bicyclists that break the rulesof-the-road. Do bicyclists fit the popular image of rude, reckless, and lawbreaking roadway users? If so, what factors moderate such behaviors? If not, how should we characterize the behaviors of bicyclists?

Proven effective for reaching sample populations identified as hard-to-reach, we employed a snowball-sampling framework and an online, scenario-based survey that received nearly 18,000 responses. Via multi-level statistical analyses, we combine data from the online survey with city-level infrastructure data to identify factors significantly associated with a spectrum of illegal bicycling activities. As bicycling continues to proliferate in cities, a more defined characterization of illegal bicycling behaviors and the motivations behind such behaviors will inform practice and help improve our cities and transport systems.

The next section begins with a literature review of the limited bicyclist behavior research before expanding into the driver behavior literature to see what may be applicable. The background section then delves into the research looking at the societal consequences of lawbreaking behaviors by mode as well as how road users explain their illegal behaviors.

\section{Background and literature review}

\subsection{Unlawful bicyclist behavior}

Despite being an issue that garners attention from the popular press, the literature on law-breaking behavior among bicyclists is relatively scarce and almost exclusively international. The most relevant study surveyed just over 2,000 Australian bicyclists and found that $37.3 \%$ had at some point illegally ridden through a red light, with higher rates of non-compliance for younger people and males (Johnson et al., 2013). A smaller Brazilian survey found a similar non-compliance rate of $38.4 \%$ but focused entirely on male, commuter bicyclists because this subgroup was thought have the highest road safety risk (Bacchieri et al., 2010).

Beyond the survey-based work, we identified limited examples of observational studies of bicyclist behavior at intersections. One Australian study found that $6.9 \%$ of more than 4,000 bicyclists violated red traffic lights (Johnson et al., 2011). However, this percentage dropped to 5.1\% when discounting

${ }^{1}$ Australians drive (and bicycle) on the left side of the road. 
those that made an illegal left-turn on red ${ }^{1}$, which despite being a violation, the authors perceived as a "safe" maneuver. Moreover, red-light-running rates decreased significantly when cars or others bicyclists were present and adhering to the law. This led the authors to conclude that the problem of running red lights by bicyclists is not as widespread as drivers seem to perceive (Johnson et al., 2011). Other unpublished Australian studies found red-light-running rates in the 7\% the 9\% range (Daff \& Barton, 2005; Johnson, Charlton, \& Oxley, 2008).

Two unpublished American papers suggest similar numbers. One study of 4,300 New York City bicyclists found that $34 \%$ of bicyclists fail to come to a complete stop at red lights (Tuckel \& Milczarski, 2014). Females and bike share users both had better rates of compliance. Another study of over 2,000 bicyclists across four cities in Oregon saw an overall infringement rate of just over 6\% (Anderson, 2013).

Most of the existing bicyclist behavior research focuses on violation rates based upon a binary assessment of road users that does not adequately reflect the gradations of illegal bicycling behaviors. Our work seeks to fill this gap in the literature.

\subsection{Unlawful driver behavior}

What might be transferable from the driver behavior literature to our study of bicyclists are the violation rates and the associated risk factors. For instance, the same authors of the above unpublished NYC bicycling study also investigated rates of red light compliance for over 4,300 drivers at fifty randomly selected intersections across NYC (Tuckel, Milczarski, \& Rubin, 2014). Focusing on the first vehicle to arrive at the intersection once the light turned red, $8.7 \%$ of drivers failed to beat the red light but still drove through it. Two intersections saw driver red-light-running rates higher than $30 \%$ with one particular intersection seeing more than $37 \%$ of drivers running the red light (Tuckel et al., 2014). Gender was not significant, but taxi drivers and streets with multiple travel lanes tended to have higher rates of non-compliance.

While other researchers tended to find lower red-light-running rates for drivers, these papers typically normalized their non-compliance rates by every car on the road, including those with no opportunity to run the red light (Retting, Williams, \& Greene, 1998; Retting et al., 1999). Still, one of the more comprehensive papers on this topic reviewed more than 2,700 hours of video and found that, on average, a typical intersection would see three drivers running a red light each hour (Retting et al., 1998). Despite $93 \%$ of respondents from another survey saying that running a red light in a car is unacceptable, more than one-third of the same respondents report doing so within the last thirty days (AAA, 2010). Red-light running by drivers is so prevalent that Google — after analyzing data from more than 1.7 million miles driven over the last six years by their fleet of over twenty autonomous cars-programs their autonomous cars to pause for a second after the light turns green (Urmson, 2015).

The relative prevalence of drivers running red lights is somewhat surprising, but speeding is even more widespread and perhaps a better comparison for illegal bicycling behavior because the perceived negative externalities are lower than for drivers running red lights. One example from this strand of research is NCHRP Report 504, which found that only $23 \%$ of free-flow vehicles were at or below the posted speed limit on suburban and urban collector roads located across seven U.S. cities (Fitzpatrick et al., 2004). On local roads, this percentage increased to $52 \%$, but this still means that almost half of drivers exceeded the speed limit on local roads in populated areas (Fitzpatrick et al., 2004). A report published by the Royal Automobile Club suggests very similar numbers for drivers in England (RAC, 2007), and a study from Sweden found that more than $50 \%$ of drivers exceeded the speed limit by more than $10 \mathrm{~km} / \mathrm{h}$ (Haglund \& Åberg, 2000).

In terms of risk factors that may also extend to bicyclists, most papers suggest that male drivers are more likely to speed than females (Conner, Smith, \& McMillan, 2003; Constantinou et al., 2011,; 
Rhodes and Pivik, 2011). Stradling et al., however, found no significant difference between speeding prevalence by males and females, but males were much more likely to drive well in excess of the speed limit (Stradling et al., 2003). The other overarching factor identified by this strand of literature was the significance of age, with younger drivers being more likely to speed (Stradling et al., 2003; Constantinou et al., 2011; Rhodes \& Pivik, 2011; Hatfield \& Fernandes, 2009). Beyond the tendency for more risky behaviors among younger road users, the literature also suggests that inexperienced drivers tend to underestimate risk (Machin \& Sankey, 2008).

\subsection{Safety consequences of unlawful driving and bicycling}

While almost all drivers admit to occasionally breaking traffic laws, most offenders do not believe their actions carry increased risk (Corbett \& Simon, 1992). They might be right since the average driver is involved in an injury crash once every 57 years, and only 1 in 80 drivers is ever involved in a fatal crash (Forsyth \& Silcock, 1987). Then again, red-light running is the single most common cause of total urban crashes and urban crashes resulting in an injury or fatality (Retting et al., 1995). While the risks associated with a driver running a red light are obvious, speeding also plays a role in more than $30 \%$ of fatal U.S. crashes (USDOT, 2014). A synthesis paper from Elvik concluded "that the relationship between speed and road safety is causal, not just statistical" (Elvik, 2005). In a later paper, Elvik's research suggests that eliminating speeding would cut road fatalities between $25 \%$ and $33 \%$ in motorized countries (Elvik, 2012).

Unfortunately, many of those killed in crashes caused by lawbreaking drivers can be classified as innocent victims (Chong et al., 2010). In red-light crashes, more than half of those killed are someone other than the person that ran the red light (IIHS, 2007). A San Francisco study finds that one-third of pedestrian fatalities occurred in a crosswalk when the pedestrian had the right-of-way (Elinson, 2013). In a study of pedestrian fatalities in French cities, this percentage jumps to more than 50\% (ONISR, 2013). Given other studies showing that more than $50 \%$ of drivers do not stop for pedestrians when waiting at a crosswalk, such statistics regarding victimization of innocent road users are not surprising (APR, 1998). However instead of focusing on poor driver behavior, the related research strand finds mid-block crossings to be ineffective, and in terms of safety outcomes, worse than providing no pedestrian infrastructure (Gibby et al., 1994). It is also common for the media to label such tragic events as "accidents" as opposed to trying to hold drivers accountable for criminal behavior (Schmitt, 2015). Despite our unwillingness as a society to prosecute or brand someone a criminal for such behaviors, the research suggests that illegal driving behaviors — even if seemingly innocuous — are inextricably linked to more crashes (Iversen, 2004; Elvik, 2005; Retting, Ulmer, \& Williams, 1999).

The safety-related consequences of lawbreaking bicycling are less clear than those related to lawbreaking driving. Several studies look at the issue of "unsafe" bicycling and conclude that a lack of bicycle law enforcement contributes to poor road safety outcomes (Beck, 2007; Lavetti \& McComb, 2014). However, these same studies confound the issue by not looking at actual crash data and assuming that illegal bicycling equates to unsafe outcomes. The studies that do delve into actual crash data find relatively few instances of unlawful bicycling being listed as a contributing crash factor (Johnson et al., 2011). The results range from less than $2 \%$ of bicycle-motor vehicle crashes being caused by bicyclists running red lights in the United Kingdom (Lawson, 1991) to around 6\% in Australia (Green, 2003; Schramm, Rakotonirainy, \& Haworth, 2008). Overall, the chance of an innocent road user being injured or killed by an unlawful bicyclist tends to be much lower than by a lawbreaking driver (Chong et al., 2010; IIHS, 2007). Moreover, the aforementioned study of male, commuter bicyclists from Brazil suggested that bicyclists running red lights were not significantly associated with crash outcomes (Bacchieri et al., 2010).

Some places allow bicyclists to treat stop signs as yield signs and red lights as stop signs. More com- 
monly known as the Idaho Stop Law, which was passed for the entire state of Idaho in 1982, these rules also apply in several Colorado cities and in parts of Paris, France (Stromberg, 2014; Chappell, 2015). San Francisco and Colorado are currently considering adopting similar rules (Holson, 2015). Critics of the law cite safety concerns, and from the perspective of a driver, bicyclists running through intersections without coming to a complete stop indeed sounds dangerous. However, the results from Idaho suggest improved bicyclist safety after the law was put in place (Meggs, 2011, 2010).

\subsection{How do road users explain their illegal behaviors?}

Most drivers self-report breaking the law in order to save time (Kanellaidis, Golias, \& Zarifopoulos, 1995; Fleiter, Lennon, \& Watson, 2010, 2007). However, there is very little academic research regarding the rationale for why bicyclists break the law, which is another gap in the literature that this paper seeks to fill. The previously discussed Australian survey conducted by Johnson et al. asked this question and found that most bicyclists only behaved unlawfully in situations with minimal conflicts (i.e., turning on red, when nobody was around, or at a pedestrian crossing) or when an inductive loop at a traffic signal did not detect their bicycle (Johnson et al., 2013). Overall, the results from Australia suggest that most bicyclists only break the law when they perceive their behavior is safe.

While saving time might also be important to lawbreaking bicyclists, popular press articles suggest that bicyclists sometimes break laws in order to increase their own perceived safety (Kelly, 2014). For instance, some bicyclists feel that perfectly legal bicycling maneuvers — such as "taking the lane" — cede too much control of the situation over to the drivers. Thus, on seemingly dangerous roads, they would rather ride illegally on the sidewalk than risk getting hit by an inattentive driver (Marohn, 2014; Grabar, 2013; Kelly, 2014). Such fears may not be warranted in terms of actual road safety outcomes, but it is worth noting that many crashes are caused by drivers who look for-but fail to see-bicyclists (Herslund \& Jorgensen, 2003). Bicyclists are also the most likely road users to report near-hit crashes at the rate of one every 5.6 miles (Joshi, Senior, \& Smith, 2001). As a result, self-preservation seems to be at the forefront of most bicyclists' mind, and many do not feel comfortable bicycling in traffic (Wood et al., 2009). Other reasons given by bicyclists for breaking the law relate to saving energy (Stromberg, 2014). A well-known article by Fajans and Curry suggests that bicyclists use 25\% less energy in getting back to $10 \mathrm{mph}$ when slowing to $5 \mathrm{mph}$ rather than coming to a complete stop (Fajans \& Curry, 2001).

The perception of bicyclists as iconoclasts may very well be true, at least for some riders, and play a role in their unlawful bicycling behaviors (Furness, 2010). They also might break laws, as some drivers do, simply for fun. Beyond examining the characteristics of lawbreaking road users and searching for related factors, we also seek to better understand the rationale behind the illegal behaviors of bicyclists. The next section details the survey methods and data collected before then describing the statistical methodology.

\section{Research strategy, methodology, and data}

The intent of this research was to gather information regarding bicycling behaviors potentially construed as rude, reckless, and unlawful in order to understand the characteristics and motivations of such road users and inform multi-modal transportation practice and policy.

Conventional survey techniques are increasingly plagued by decreasing response rates, which leads to low quality in terms of reliability and validity (Dusek, Yurova, \& Ruppel, 2015). These issues are exacerbated when the population of interest engages in illegal behavior (Biernacki \& Waldorf, 1981), is geographically dispersed or international (Dusek, Yurova, \& Ruppel, 2015), or could be described as "urban elite" (Atkinson \& Flint, 2001). Traditional household surveys (such as random mailings/ 
dialings and door-to-door techniques) have been shown to underrepresent-or completely miss—such hard-to-reach groups to the point where random sampling with such techniques is unattainable (Watters \& Biernacki, 1989; Van Meter, 1990; Atkinson \& Flint, 2001; Dusek, Yurova, \& Ruppel, 2015). Moreover, the research suggests that probability samples are impractical at-best, and more likely impossible, when it comes to trying to survey difficult-to-reach or rare populations (Codina et al., 1999; Handcock \& Gile, 2011; Kalton \& Anderson, 1986; Salganik \& Heckathorn, 2004; Thompson \& Collins, 2002).

While bicycling rates continue to increase, bicycling still only comprises $0.6 \%$ of work trips in the U.S. (ACS, 2014). Bicyclists, in general, remain a rare subset of the population that is difficult to survey using probability-based samples (Götschi et al., 2011), and bicycle travel tends to be systematically underreported in national surveys (Krizek, Handy, \& Forsyth, 2009). Researchers conducting survey work have long recognized that younger, male populations can be hard-to-reach with conventional population-based surveying techniques (Atkinson and Flint, 2001). And as described in the previous section, the existing literature regarding illegal and/or reckless driving behavior suggests that both younger drivers (Stradling et al., 2003; Constantinou et al., 2011; Rhodes \& Pivik, 2011; Hatfield \& Fernandes, 2009) and male drivers (Conner, Smith, \& McMillan, 2003; Constantinou et al., 2011; Rhodes \& Pivik, 2011) are more likely to exhibit such behaviors. If young males bicycle like the research suggests they drive, then looking beyond traditional survey strategies is needed (Atkinson \& Flint, 2001). Accordingly, we created a survey instrument that would adequately reach those that may engage in illegal bicycling behaviors by combining snowball and online methods.

\subsection{Snowball sampling framework}

First developed by Coleman in the late 1950s as an approach for studying social networks, snowball sampling has evolved into a methodology for finding research subjects that is particularly effective at surveying those that may be reluctant to complete traditional surveys and/or finding populations that engage in illegal behavior (Atkinson \& Flint, 2001; Coleman, 1958; Katz \& Lazarsfeld, 1955; Merton, 1949; Trow, 1957). While snowball sampling frameworks challenge traditional sampling convention, they have proven to be more efficient and effective than traditional techniques when attempting to sample hard-to-reach populations (Atkinson \& Flint, 2001; Biernacki \& Waldorf, 1981; Sadler et al., 2010; Singh, Pandey, \& Aggarwal, 2007). This is particularly true when the research is largely exploratory or attempting to generate low-level descriptive theories such as we are trying to accomplish with these research activities (Hendricks, Blanken, \& Adriaans, 1992; Kalton \& Anderson, 1986; Penrod et al., 2003; Streeton, Cooke, \& Campbell, 2004). Snowball sampling has been used to study illegal behaviors (Avico et al., 1988; Fitzgerald, 1996; Griffiths et al., 1993; Inciardi \& Russe, 1977; Kaplan, 1987; McNamara, 1994; Patrick, 1973, Thompson \& Collins, 2002; Valdez \& Kaplan, 1999; Valdez, Kaplan, \& Codina, 2000; Whyte, 1955; Wright \& Decker, 1997; Wright et al., 1992); the seriously ill (Pollok \& Schlitz, 1988; Sudman \& Freeman, 1988; Tabnak \& Sun, 2000; Thompson \& Collins, 2002; Watters and Biernacki, 1989); and even jazz musicians (Heckathorn \& Jeffri, 2001). We considered a respondent-driven sampling (RDS) framework but determined that snowball sampling was a better fit since the population of interest is not necessarily socially networked (Johnston \& Sabin, 2010).

Self-selection bias is most often considered the main disadvantage of snowball sampling frameworks (Berk \& Ray, 1982; Kaplan, 1987; Van Meter, 1990; Winship \& Mare, 1992). While traditional probabilistic sampling techniques can similarly be criticized (Groger, Mayberry, \& Straker, 1999; Sadler et al., 2010), this shortcoming can partly be addressed in snowball surveys with larger sample sizes (Pollok \& Schlitz, 1988; Salganik \& Heckathorn, 2004; Van Meter, 1990), and our survey collected close to 18,000 respondents. Large samples can also help reduce random-sampling errors (Van Meter, 1990); 
however, it is also advisable to refrain from weighting snowball samples (Salganik \& Heckathorn, 2004).

\subsection{Online survey approach}

Online surveys have also proven effective with potentially difficult-to-reach groups, at increasing sample size, with overall representativeness (Baltar \& Brunet, 2012; Benfield \& Szlemko, 2006; Dusek, Yurova, $\&$ Ruppel, 2015), as well as when asking people to disclose illegal activities (Khazaal et al., 2014; Ramo \& Prochaska, 2012; Van Selm \& Jankowski, 2006). Online surveys can reduce costs, increase efficiency for both the respondent and the surveyor, and facilitate a variety of question types and logic-based question trees more likely to be answered in the intended order (Baltar \& Brunet, 2012; Evans \& Mathur, 2005; Van Selm \& Jankowski, 2006). Long-distance and international mail surveys typically have very low response rates, so online surveys are useful when surveying geographically diverse populations (Dusek, Yurova, \& Ruppel, 2015; Harzing, 1997). Online survey can also eliminate interviewer bias and data entry errors (Brennan, Rae, \& Parackal, 1999; Medlin, Roy, \& Ham Chai, 1999; Mehta \& Sivadas, 1995; Smith, 1997; Van Selm \& Jankowski, 2006).

The main drawback of online surveys has historically been the known bias against those without internet access. Scholl et al. (2002) suggests that this lack of representativeness - and the skewed attributes of population with access to the internet-are fading over time with exponentially increasing rates of online access (Evans \& Mathur, 2005; Scholl, Mulders, \& Drent, 2002). Now, there are more than 3.4 billion internet users worldwide, which represents more than $46 \%$ of the world's population (Internet Live Stats, 2016). Despite the non-probabilistic nature of internet surveys, the research suggests that the quality of the data is at least equivalent to traditional surveys (Gosling et al., 2004; Khazaal et al., 2014; Ritter et al., 2004; Whitehead, 2011) and valid for making statistical inferences (Baltar \& Brunet, 2012; Wong, 2008). However with online surveys, we can neither calculate sampling errors nor response rates (Van Selm \& Jankowski, 2006).

\subsection{Survey description}

Using a snowball sampling framework, we conducted an online, convenience-based survey of road users (bicyclists in addition to drivers and pedestrians). The Institutional Review Board (IRB) at the University of Colorado Denver approved all survey questions and recruitment methods. Participants aged 18 years or older were eligible to partake in this voluntary study and were provided a description of the effort before consenting to do so. Existing research suggests that the academic nature of an online survey should be clear, which we made sure to present at the outset of the survey description (Dusek, Yurova, $\&$ Ruppel, 2015). The full survey included nearly 100 questions and took 15-20 minutes to complete. Our sample was unrestricted, meaning that anyone with access to the internet could complete the survey (Van Selm \& Jankowski, 2006). We offered no compensation to respondents. The survey opened in early January 2015 and closed in March 2015. Over the course of that time frame, the survey gained attention in the popular press (Badger, 2015; Simcoe, 2015) and was subsequently promoted via wordof-mouth and social media, which resulted in a large, multi-national "opportunistic" snowball sample (Kemper, Springfield, \& Teddlie, 2003). In total, we collected 17,851 responses from 73 countries. From that total, 14,341 responses were from the United States with the rest spread around the globe with most from Europe, Australia, and Canada.

The core of the survey was a series of hypothetical bicycling scenarios, each including a picture of a specific bicycling situation and a short description. The survey then presented multiple choice responses. Figure 1 depicts an example of this type of question. Each scenario presented one completely lawabiding option and a range of unlawful alternatives. The illegal options typically covered three catego- 
ries: i) relatively minor infringement with minimal risk or potential conflicts; ii) major infractions with increased risk and potential for conflict; and iii) reckless behavior with potential to endanger themselves and/or others. We also inquired about typical behaviors as a pedestrian or driver (when applicable). If respondents acknowledged any law-breaking behavior for the various modes, we asked their rationale for doing so (e.g., saving time, saving energy, personal safety, to make myself more visible to other road users, a social/political statement, because it is fun, and to elicit a response from other road users) and via open response.

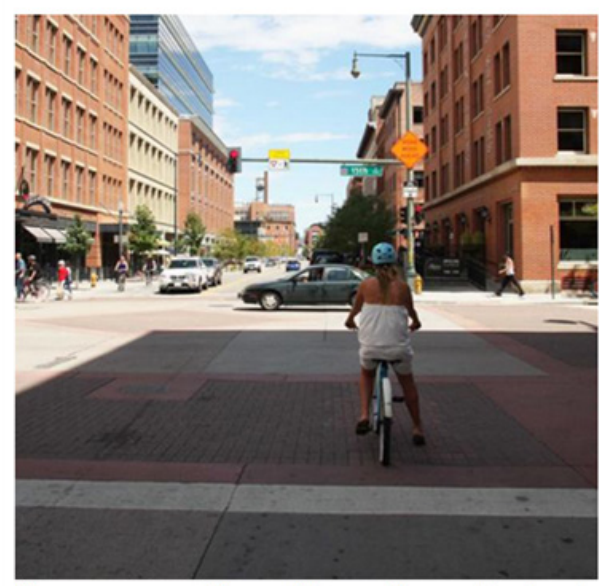

You are approaching an intersection on the street pictured above and the light is red. How do you proceed?

Stop and wait for a green light

Stop and proceed through the red light if there is no traffic

Slow down - but not stop - and proceed through red light if there is no traffic

Continue through red light without slowing down much at all

Any additional comments to help us understand your choice?

Figure 1: Example scenario question from survey

In addition to the scenario-based road user questions, we asked respondents various demographic and socio-economic status questions (e.g., age, gender, race/ethnicity, children in household, education, income, political affiliation, access to automobile, etc.) as well as questions regarding their bicycling experience and bicycle usage. This included questions regarding: how often the respondent rides recreationally (i.e., for fun or exercise) and for utilitarian purposes (i.e., to get somewhere); how well they know the rules of the road; how often they rode a bicycle as a child; and the degree to which they "take the lane" in mixed traffic situations ${ }^{2}$. We also asked bicyclists about their level of comfort in six contexts that varied by the degree of mixed traffic and the type of bike infrastructure (ranging from off-street paths with no automobiles to streets with high levels of fast-moving car traffic adjacent to the bicyclist). In terms of connecting this rider typology variable with the literature, we employed what is known as the Portland typology, which categorizes individuals into four basic bicyclist groups: no way, no how; interested but concerned; enthusiastic and confident; and strong/fearless (Dill \& McNeil, 2013). Using a

\footnotetext{
${ }^{2}$ Taking the lane refers to the vehicular cycling practice of traveling near the center of a travel lane in order to control the lane, avoid the door zone of parked cars, and prevent cars from passing too closely. While legal, taking the lane is often interpreted by drivers as rude or reckless. Many bicyclists also find this behavior uncomfortable, especially on busy arterials, and instead ride on the sidewalk even when doing so is illegal.
} 
7-point Likert scale for each pictured context (ranging from "completely uncomfortable" to "completely comfortable"), we then aggregated the responses and operationalized this variable on the same scale, with a one representing someone completely uncomfortable riding a bicycle and a seven representing someone completely comfortable riding in almost all situations.

The survey also included geographic questions (i.e., where they live now and where they grew up) in order to gauge the influence of context and place on the results. We geocoded each respondent's home location and childhood home to the city-level for the U.S. and Canada and to the country-level for the rest of the world. In order to control for differences between home locations, we sought data theoretically relevant to what might influence bicyclist behavior such as bicycle infrastructure and bicyclist safety outcomes. Unfortunately, such data was generally difficult to acquire in a comparable format, particularly internationally. We obtained bicycle-to-work mode share data from the 5-year American Community Survey (2010-2014) for all geocoded U.S. respondents.

Previous research suggests that intersection density is highly associated with overall road safety, bicyclist road safety, bicyclist mode choice, vehicle miles traveled, and public health outcomes (Marshall \& Garrick, 2010a, 2011b, 2011a, 2010b; Marshall, Piatkowski, \& Garrick, 2015; Marshall \& Garrick, 2012). Therefore, we calculated intersection density for geocoded U.S. respondents by tallying the total number of nodes or intersections, including the number of dead ends, and dividing it by the area in square miles. Finally, we acquired city-level bicycling-related data from the Alliance for Biking and Walking that was collected for their 2014 Benchmarking Report (Milne \& Melin, 2014). This included numerous theoretically relevant variables such as mileage of bike facility by type, density of bike facility by type, bicyclist fatalities per 10,000 bicycling commuters, percent of bicycle commuters that are women, and the number of youth that completed a bicycling education class. This Alliance for Biking and Walking data, however, was only available for the fifty most populous U.S. cities, which limited portions of our analysis to just those 5,636 geocoded respondents that live in those cities.

Whenever possible, we coded the survey data in a manner that facilitated further quantitative analyses. For example, with the question regarding level of education, we aggregated the data into an education score. Scores ranged from one to four according to the highest level of education received with:

- No high school diploma $=1$

- High school graduate or GED = 2

- Bachelor's degree $=3$

- Graduate degree $=4$

We employed a similar approach for other variables of interest. For example, with the bicycle scenario questions, we created lawbreaking bicyclist threshold scores on scale of 1 to 10 ranging, as shown in Figure 2, with:

- 1 = Law abidance

- $1<$ Relatively minor infringement $\leq 5$

- $5<$ More major infractions (but still not reckless behavior) $\leq 8$

- $8<$ Reckless endangerment $\leq 10$

Responses for each bicycling scenario question were placed on this scale and aggregated for each respondent. With seven scenario questions, the minimum possible sum was a 7 , which would signify a full law abider. At the other end of the spectrum, the maximum possible sum turned out to be a 58 (while every question had a full law abiding response, not every question had a response that would qualify as reckless endangerment). These sums were then standardized to a 1 to 10 scale in order to represent lawbreaking bicyclist threshold scores for each respondent. Figure 2 depicts a histogram of the distribution of lawbreaking bicyclist scores for the overall dataset. 


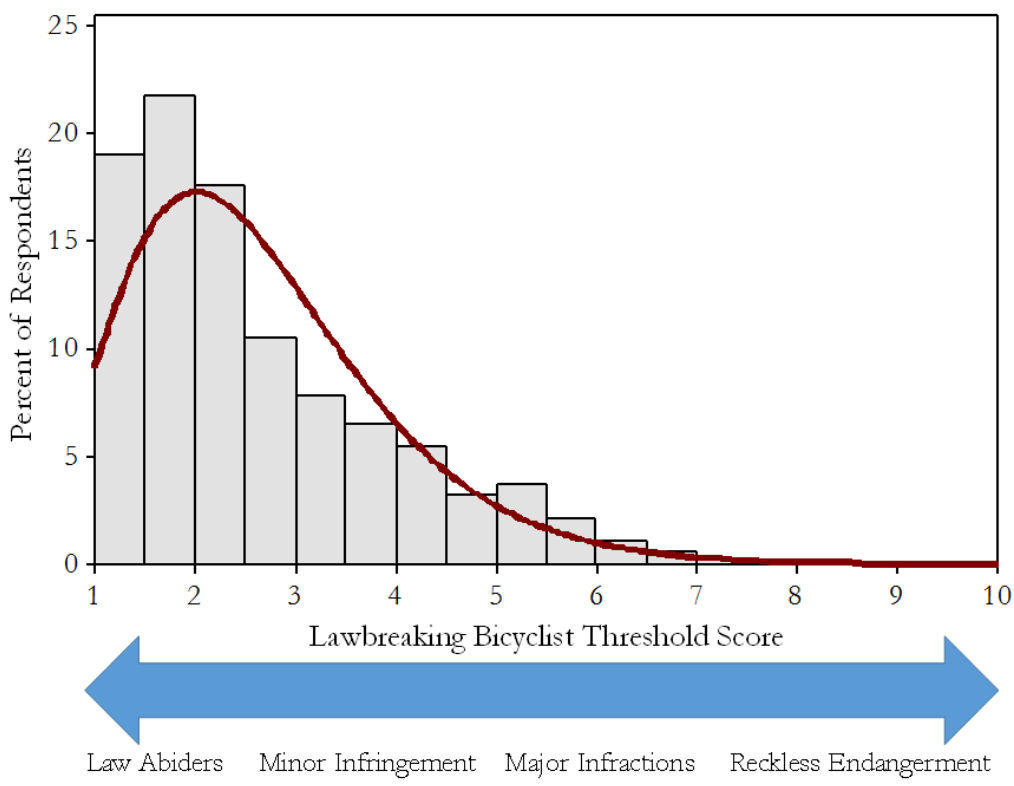

Figure 2: Lawbreaking bicyclist threshold scores and histogram of distribution

Table 1 displays descriptive statistics for selected variables. The block structure shown vertically on the far-left of the table corresponds to the statistical approach described in the next section. Figures $3 \mathrm{a}$ and $3 \mathrm{~b}$ depict the various factors with respect to unlawful bicycling behavior via stacked bar charts. Here, the relative distributions of illegal behavior categories become clearer and facilitate a better understanding of the data collected. In the overall dataset, for example, $4 \%$ of respondents that bicycle could be considered full law abiders, just over $79 \%$ were classified under minor infractions, $16 \%$ as major infractions, and $0.6 \%$ under reckless endangerment. As age increases, for instance, the relative distributions slowly shift toward lower levels of unlawful bicycling behaviors. We also see some variables - such as those with little knowledge regarding the rules of the road - with a somewhat higher percentage of reckless endangerment riders. While this suggests that better education about the rules of the road might be worth pursuing in attempting to reduce incidences of reckless bicycling, we hesitate to offer recommendations prior to statistical analysis. 
Table 1: Descriptive statistics (selected variables)

\begin{tabular}{|c|c|c|c|c|c|c|}
\hline & Variable & Obs & Mean & SD & Min & Max \\
\hline \multicolumn{7}{|c|}{ Dependent Variable } \\
\hline & Lawbreaking Bicyclist Thresholds & 17,226 & 2.64 & 1.37 & 1.00 & 10.00 \\
\hline \multicolumn{7}{|c|}{ Individual Level V ariables } \\
\hline \multirow{7}{*}{ 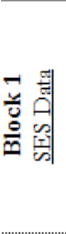 } & Age & 16,947 & 40.29 & 12.83 & 21 & 70 \\
\hline & Gender $(0=$ female; $1=$ male $)$ & 16,975 & 0.65 & 0.48 & 0 & 1 \\
\hline & Household Income (in 1000s) & 14,960 & 88.01 & 43.51 & 25 & 150 \\
\hline & Education Score & 16,833 & 3.24 & 0.72 & 1 & 4 \\
\hline & Children Under 16 in Household & 13,192 & 0.30 & 0.46 & 0 & 1 \\
\hline & Access to Automobile $(0,1)$ & 15,528 & 0.74 & 0.44 & 0 & 1 \\
\hline & Binary $(0,1)$ for non-white $(0=$ white; $1=$ non-white $)$ & 15,920 & 0.03 & 0.18 & 0 & 1 \\
\hline \multirow{6}{*}{ 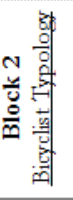 } & Recreational Bicycling ( $0=$ Never; $1=$ Infrequently; $2=$ Sometimes; $\hat{3}=$ Frequently; $4=$ Always) & 17,552 & 2.73 & 0.94 & 0 & 4 \\
\hline & Utilitarian Bicycling ( $0=$ Never; $1=$ Infrequently; $2=$ Sometimes; $3=$ Frequently; $4=$ Always) & 17,521 & 2.62 & 1.04 & 0 & 4 \\
\hline & Rules of the Road Knowledge ( $0=$ Not at All; $1=$ Not Very Well; $2=$ Well; $\hat{3}=$ Fairly Well; $4=$ Extremely Well $)$ & 17,034 & 3.31 & 0.76 & 0 & 4 \\
\hline & Taking the Lane ( $0=$ Never; $1=$ Infrequently; $2=$ Sometimes; $3=$ Frequently; $4=$ Always $)$ & 17,470 & 1.66 & 1.22 & 0 & 4 \\
\hline & Portland Typology Score & 17,510 & 5.28 & 1.04 & 1 & 7 \\
\hline & Childhood Bicycling ( $0=$ Never; $1=$ Infrequently; $2=$ Sometimes; $3=$ Frequently; $4=$ Always) & 17,542 & 2.82 & 0.84 & 0 & 4 \\
\hline \multicolumn{7}{|c|}{ City Lovel Variables } \\
\hline \multirow{7}{*}{ 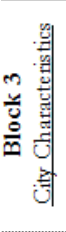 } & Intersection Density (intersections per sq. mi.) & 11,662 & 194.72 & 107.40 & 1 & 566 \\
\hline & Bicycle Mode Share (2012 Place Level ACS Data) & 11,729 & 2.18 & 2.31 & 0.0 & 31 \\
\hline & Miles of Bike Lanes + Bike Paths per sq. mi. & 5,636 & 2.10 & 0.96 & 0.2 & 4.0 \\
\hline & Miles of Cycle Tracks per sq. mi. & 5,636 & 0.07 & 0.09 & 0.0 & 0.30 \\
\hline & Bicyclist Fatalities for every 10,000 Bicyclists (average from 2009 to 2011) & 5,636 & 3.85 & 4.83 & 0.0 & 42 \\
\hline & Percent of Bicycle Commuters that are Women & 5,636 & 30.04 & 6.70 & 4 & 41 \\
\hline & Avg. Annual \# of Youth Taking Bicrcling Education Classes (2009 - 2012) & 5,636 & $6,435.2$ & $8,075.9$ & 0 & 26754 \\
\hline
\end{tabular}

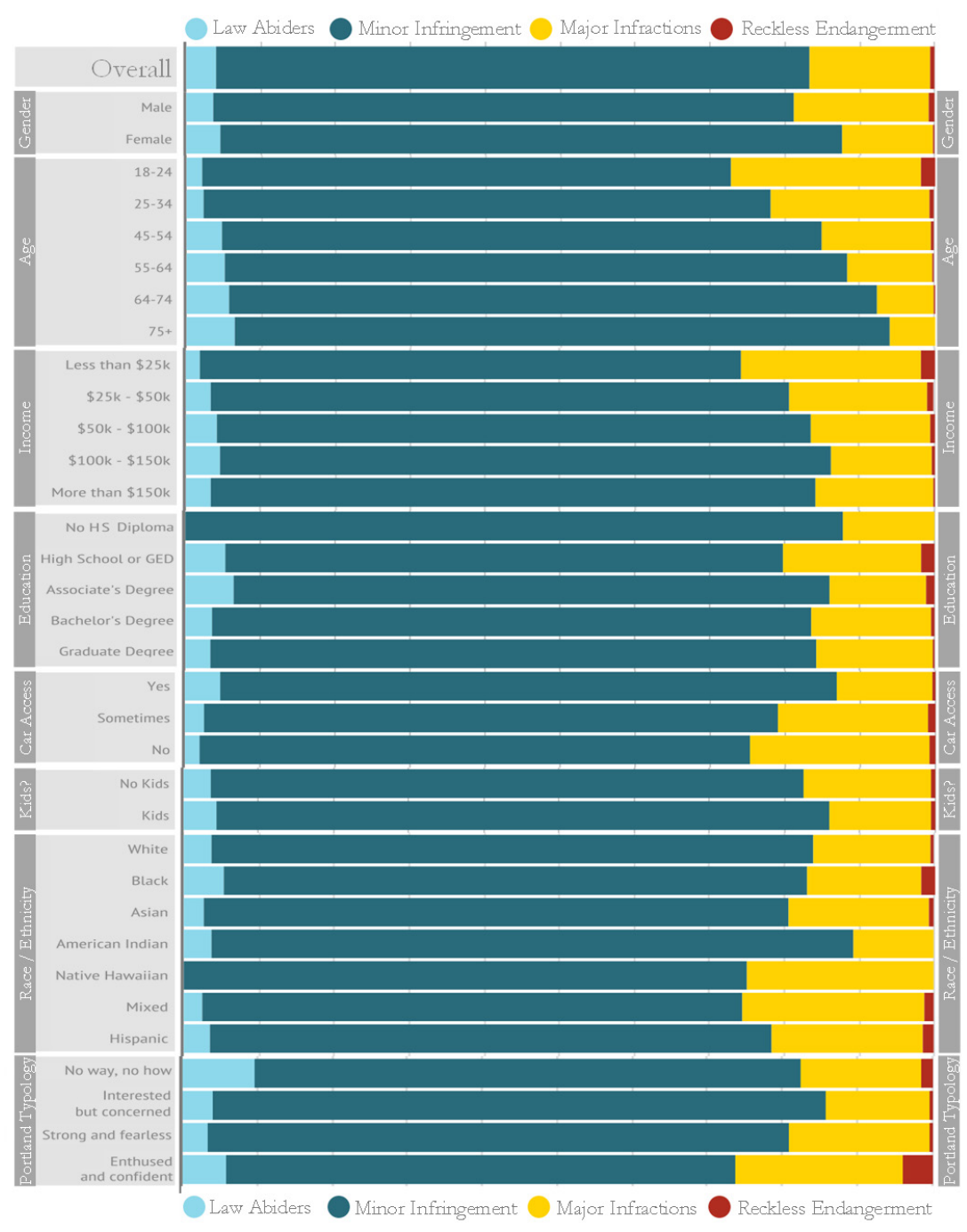

Figure 3A: Distribution of lawbreaking bicyclist types by category 


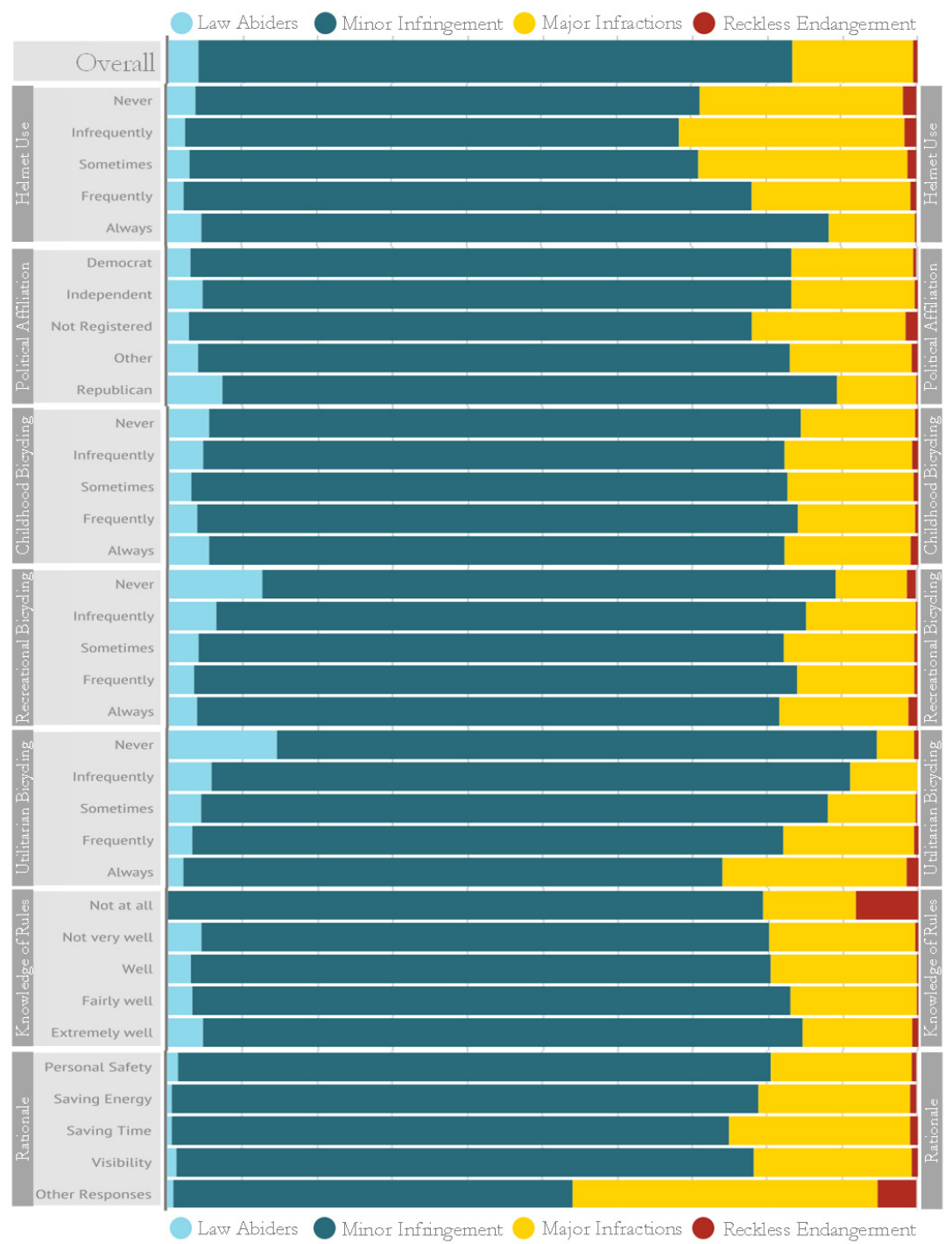

Figure 3B: Distribution of lawbreaking bicyclist types by category

\subsection{Statistical methodology}

The dependent variable for the statistical analyses is the lawbreaking bicyclist score. To better illustrate the relative influence of the independent variables, we aggregated into three blocks:

- Block 1: individual-level socio-demographic and socio-economic status measures

- Block 2: individual-level bicyclist typologies

- Block 3: city-level characteristics

Each block of variables was tested separately and then sequentially added to the statistical model. This approach has been applied in a similar manner in the risk-taking research (Ouimet et al., 2008; Vingilis et al., 2013) and crash analysis literature (Chen et al., 2005; Dissanayake and Lu, 2002; Jung, Qin, \& Noyce, 2010). When including only Block 1 and/or Block 2, the resulting statistical models encompass the entire dataset and respondents from all countries (although individual respondents were excluded if they opted not to answer a question significant to the statistical model). Due to the data limitations with city-level characteristics described above, the Block 3 models comprise 
only U.S. respondents.

We then tested the main research questions using a multilevel hierarchical random effect statistical model (Radenbush \& Bruk, 2002; Subramanian, Jones, \& Duncan, 2003; Burton et al., 2009; Healy, 2001; Li et al., 2005; Rundle et al., 2007). Our data are considered multilevel since they consist of individual-level characteristics on the first level that can be clustered into various geographies (such as by continent, country, region, state/province, or city) on the second level. The concept behind a multilevel hierarchical model is linking a pair of statistical models in order to simultaneously encapsulate both micro-level and macro-level relationships as well as the interactions between the two (Healy, 2001). Statistically, this type of structure helps account for spatial autocorrelation and the fact that respondents in the same areas share the characteristics of those areas, which would violate the independence assumption of an ordinary least squares (OLS) regression (Ewing et al., 2003). If we did not take this into account, the standard errors of regression coefficients that we are seeking to associate could be underestimated (Ewing et al., 2003). For analysis purposes, this multilevel structure also allows us to account for unmeasured differences between places.

We tested a series of multilevel models based on each geography, and the statistical models failed to converge with all geographies except the continental and city levels. For illustrative purposes, Figure 4 depicts the stacked bar results by home continent. For the sake of the multi-level statistical analyses, we focus on city-level differences in the U.S. and Canada. For the fifty largest U.S. cities, this facilitated the inclusion of the city-level bicycling infrastructure, usage, and safety variables described above under Block 3. The following represents the hierarchical structure presented:

- Level 1: Individual-Level Characteristics

- Level 2: City-Level Characteristics

With the multi-level models, the first level can be modeled as a function of the characteristics of the individual plus stochastic random error (Ewing et al., 2003). For the second level, the intercept and coefficients are modeled in terms of geographic characteristics plus random error (Ewing et al., 2003). This multi-level approach allows each city to have a specific regression equation portraying the association between the characteristics of the individual and their respective illegal behaviors. This enables us to account for unmeasured city-level effects such as differences in context, social norms, and enforcement. The Level 1 model tested unlawful bicycling outcomes as a function of the geographic mean using the following form:

$$
\mathrm{Y}_{\mathrm{ji}}=\beta_{0 \mathrm{j}}+\beta_{1 \mathrm{j}} \mathrm{X}_{\mathrm{ij}}+\mathrm{r}_{\mathrm{ij}} \quad \mathrm{r}_{\mathrm{ij}} \sim \mathrm{N}\left(0, \sigma^{2}\right)
$$

where $Y_{j i}$ is the outcome for individual $i$ in city $j$, and $x_{i j}$ is a fixed covariate. $\beta_{0 j}$ represents the mean level of the outcome in city $j$, and $\beta_{1 j}$ represents the effect of the individual-level variable on the outcome in city j.

The expected random effects Level 2 model allows the intercept and slope to vary across geographies. The Level 2 model corresponding to a Level 1 random coefficients model is as follows:

$$
\begin{aligned}
& \beta_{0 \mathrm{j}}=\gamma_{00}+u_{0 j} \\
& \beta_{1 \mathrm{j}}=\gamma_{10}+u_{1 j}
\end{aligned} \quad\left(\begin{array}{l}
u_{0 j} \\
u_{1 j}
\end{array}\right) \sim N\left(\left(\begin{array}{l}
0 \\
0
\end{array}\right),\left(\begin{array}{ll}
\tau_{00} & \tau_{01} \\
\tau_{01} & \tau_{11}
\end{array}\right)\right)
$$

where $\gamma_{00}$ represents the overall average outcome level (at $\left.\mathrm{x}_{\mathrm{ij}}=0\right)$, and $\gamma_{10}$ is the average effect of individual variables on the outcomes. The statistical analyses were completed with SAS 9.4 using the PROC GLIMMIX procedure. PROC GLIMMIX was used instead of PROC MIXED to account for the non-normal score distribution depicted in Figures 2 and 4. Based on the observed distribution shown 
in Figure 2, we specified a gamma distribution with the PROC GLIMMIX procedure. For our specific statistical procedure, the model fit variables shown in the results table include log pseudo-likelihood and generalized chi-square. While these fit statistics cannot be compared across models, we used them to help with final variable selection. Statistical significance at three levels (i.e. $\mathrm{p}<.10, \mathrm{p}<.05$; and $\mathrm{p}<.01$ ) is noted by the asterisks in Table 3. With respect to multicollinearity, none of the variables used in the final models had a Pearson correlation coefficient higher than 0.4 .

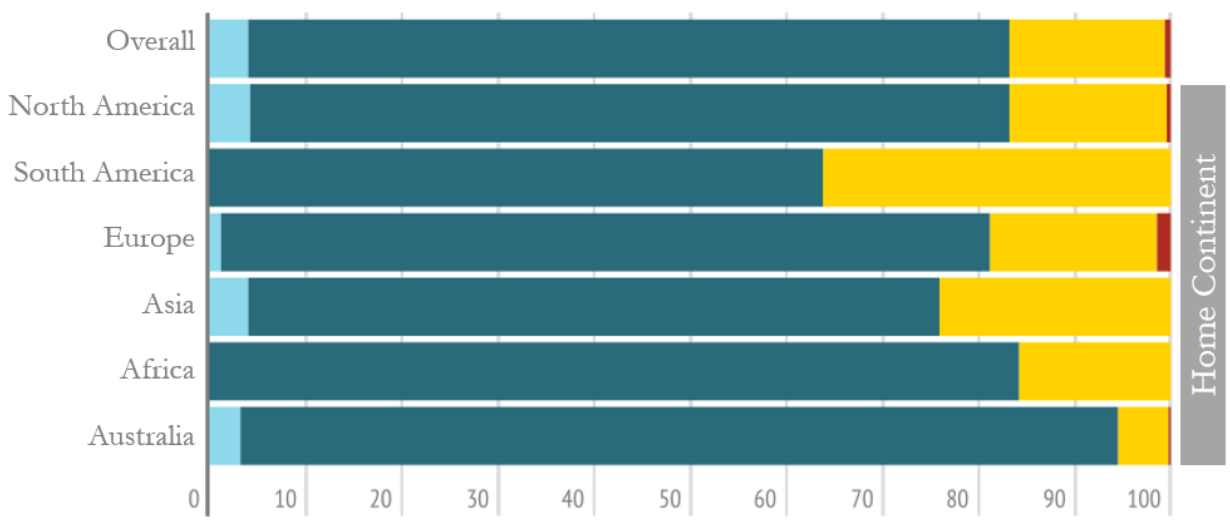

Percentage of Bicyclists by Lawbreaking Bicyclist Threshold Score by Home Continent

Law Abiders Minor Infringement Major Infractions Reckless Endangerment

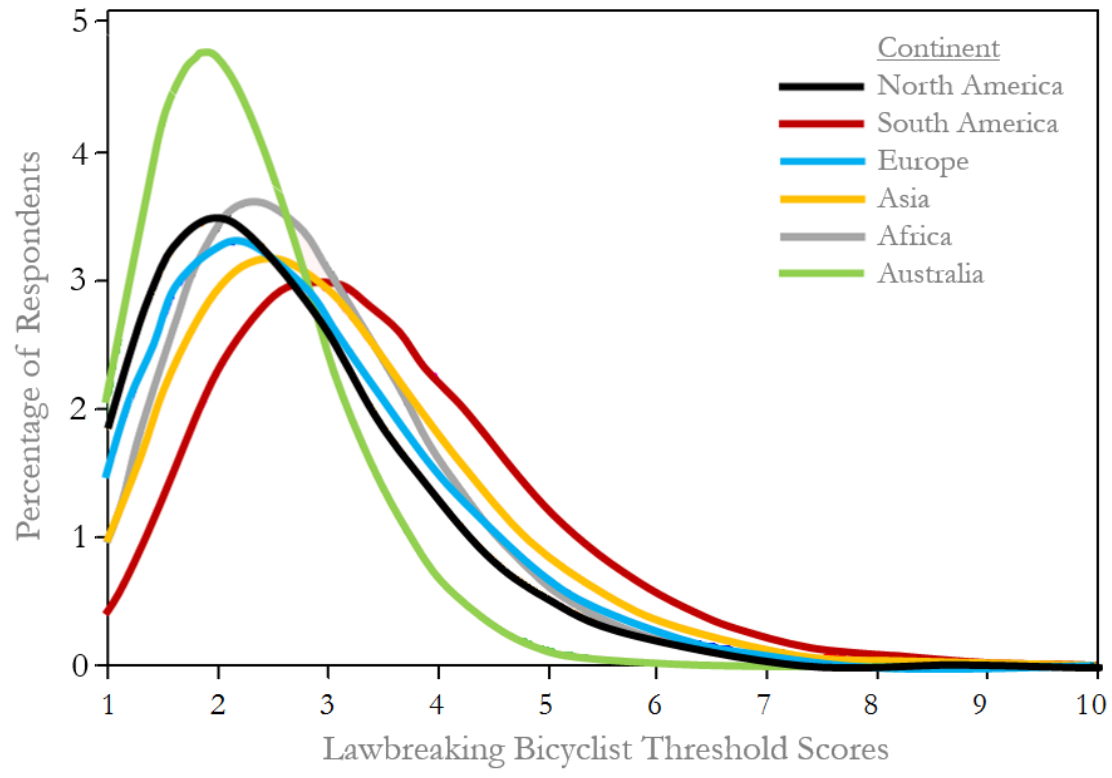

Figure 4: Continental differences and distributions

\section{$4 \quad$ Findings}

Table 2 describes the eight statistical models, and Table 3 portrays the corresponding results. While we could have focused solely on the results of the final multilevel model that includes all three blocks, we elected to include additional models that turned out to be instructive in parsing out the relative influ- 
ence of the various blocks as well as the influence of the city where one lives. As discussed in the statistical methodology section, Models 1 through 3 involve the entire international dataset (excluding individuals that failed to answer questions included in the final models). We tested each international model with U.S. respondents only, and the results remained stable (in other words, the result do not change significantly with the smaller level of geography). While Model 4 does not include the city-level variables from Block 3, it is a multilevel model that accounts for unmeasured differences between cities and includes respondents from the U.S. and Canada. When including the city-level variables in Block 3 (Models $5-8)$, the statistical model encompasses only U.S. respondents. While Models 6 through 8 include all U.S. respondents, Model 5 is further limited to respondents to the top fifty most populous U.S. cities due to the inclusion of city-level bike infrastructure data acquired from the Biking and Walking Alliance dataset. We were then able to include all U.S. respondents in Model 6, even though it was Block 3 only, because all variables from the Biking and Walking Alliance dataset turned out to be insignificant. We tested Model 6 with just respondents from the fifty most populous U.S. cities, and the results were remarkably similar to the model presented despite almost half of our U.S. respondents not being included. Table 3 orders the models as shown in Table 2 below:

Table 2: Statistical model descriptions

\begin{tabular}{cllcc} 
Model & Blocks & Block Description & Multilevel? & Level of Geography \\
\hline 1 & Block 1 only & SES & No & International \\
2 & Block 2 only & Bicyclist Typology & No & International \\
3 & Block 1 + Block 2 & SES \& Bicyclist Typology & No & International \\
\hline 4 & Block 1 + Block 2 & SES \& Bicyclist Typology & Yes & U.S. \& Canada \\
\hline 5 & Block 3 only & City-level Characteristic & No & 50 Most Populous U.S. Cities \\
\hline 6 & Block 3 only & City-level Characteristic & Yes & United States \\
\hline 7 & Block 1 + Block 2 + Block 3 & All & No & United States \\
\hline 8 & Block 1 + Block 2 + Block 3 & All & Yes & United States \\
\hline
\end{tabular}

The hierarchical terms (corresponding to variability in slopes) are significant in all three multilevel models (Models 4, 6, and 8 that appear highlighted in black in Tables 2 and 3). This indicates that we cannot reject the null hypothesis that there are no differences in slopes across cities with respect to illegal bicyclist behavior. We tested all theoretically relevant interaction terms, and those found to be significant are included in Table 3. Several variables tested were unable to be used in the final models due to high correlation with other variables including city population, population density, employment density, block size, transit mode share, pedestrian mode share, density of bike boulevards, density of colored bike lanes, number of bicycle traffic lights or bike boxes, and bike-to-work day participation rates. Where the respondent grew up was not significant in any of the models. We also did not include stated rationale for lawbreaking as a variable in the statistical models due to endogeneity issues, but we discuss self-reported rationales later in the paper. The remainder of this section is organized by variable block group and discusses the variables tested and results before then focusing on Model 8, the complete multilevel model.

\subsection{Block 1: Individual-level socio-demographic and socio-economic status measures}

In agreement with the existing research on driver behavior, younger bicyclists and male bicyclists are associated with a higher level of illegal bicycling behavior (i.e., more like to commit more major infractions). Age and gender are the only two variables from Block 1 that remain significant in every model. While access to an automobile and Hispanic ethnicity are not significant in any model, the other vari- 
ables (i.e., income, education, children in household and race) show significance in the early models but eventually fall out with the multilevel models or when accounting for the city-level characteristics.

Higher incomes generally associate with lower levels of unlawful bicycling behaviors, although the relationship is not linear. Despite the directionality of the coefficient, an individual with an income over $\$ 150 \mathrm{k} /$ year has a higher lawbreaking bicyclist score than someone around $\$ 100 \mathrm{k} /$ year (holding all other variables constant). Higher levels of education (which for our dataset is not highly correlated with income) is associated with higher levels of illegal behaviors; however, this relationship is moderated by our race variable in Model 1. If the respondent identified as non-white, then higher education associated with lower levels of unlawful bicycling behavior. This interaction term drops out when accounting for bicyclist typology in Model 2.

The results suggest having children under 16 in the household is associated with lower levels of illegal bicycling behavior; however, the reduction is significantly greater for women than for men. Identifying as non-white generally associated with higher levels of unlawful bicycling behavior, but as mentioned above, this was moderated by higher levels of education.

With the multilevel models, all of the Block 1 variables become insignificant except age, gender, and income. Income, though, becomes insignificant when accounting for city-level characteristics. This suggests that the unmeasured characteristics of the city in which one lives (e.g., context, culture, social norms, and police enforcement) and the measured characteristics of that city (i.e., intersection density and bicyclist mode share) supersede most SES variables in terms of how one behaves as a bicyclist. In other words, the lawbreaking bicyclist score has less to do with who you are than where you live.

\subsection{Block 2: Individual-level bicyclist typologies}

Bicyclists that ride more for recreational purposes tend to have lower levels of unlawful bicycling behavior, and those that ride more for utilitarian purposes skew higher (although the two bicyclist types are not mutually exclusive). Those more prone to "take the lane" tend to exhibit higher levels of unlawful bicycling behavior, but the combination of this variable with increased utilitarian bicycling moderates this association.

In Models 3 and 4, the higher degrees of bicycling comfort on busier streets (as measured by our "Portland Typology" score; see Dill \& McNeil for more information) suggests higher levels of unlawful bicycling behavior (Dill \& McNeil, 2013). Models 3, 7, and 8 all suggest a non-linear relationship where lawbreaking behavior is lowest for those falling toward the middle of the Portland Typology spectrum. In other words, inexperienced bicyclists - perhaps unfamiliar with the rules of the road or unwilling to venture beyond off-street trails — and those comfortable bicycling in almost any context tended to have higher levels of unlawful bicycling behavior than those that are comfortable bicycling on streets with better separation or less traffic.

Over the course of the model progression, the only variable significant in Model 2 from Block 2 that falls out is recreational bicycling. The influence of the other three variables (i.e., level of utilitarian bicycling, taking the lane behaviors, and the Portland Typology score) remain consistent as the models begin to shift to multilevel and include city-level characteristics.

\subsection{Block 3: city-level characteristics}

In Model 5, we test Block 3 variables and find that several city-level characteristics are significant (i.e., intersection density, bicycling mode share, cycle track density, percent of women commuters, and youth bicycling education). However, as soon as we shift to a multilevel model, every Block 3 variable but intersection density becomes insignificant, including all of the infrastructure, safety, and education vari- 
ables derived from the Biking and Walking Alliance dataset (see Table 1). While bicycling mode share becomes significant again in Model 7 (where we combine all three blocks but without multilevel), it drops out again in Model 8, which is multilevel. This suggests that the unmeasured characteristics of the city one lives in supersede most of the city-level infrastructure, safety, and education characteristics we were able to measure.

Despite the contradicting coefficient signs for the bicycling mode share variable in Models 5 and 7 , accounting for the interaction variable in Model 5 (bicycle mode share $\mathrm{x}$ intersection density) suggests that higher bike mode shares are generally associated with lower levels of unlawful bicycling behavior. The bicycling mode share variable, however, is not significant in Model 8. For Models 5 through 8, cities with higher intersection densities tend to be associated with higher levels of lawbreaking bicyclist behavior. While the bicycling mode share variable is not highly correlated with intersection density for our dataset, previous research suggests that higher bicycling mode share is associated with higher intersection densities (Ewing \& Cervero, 2010; Marshall \& Garrick, 2010b). This interface between infrastructure, mode shares, and behaviors deserves additional research.

Though recent reports and popular press articles suggest lower levels of unlawful bicycling behavior with improved bicycling infrastructure (Loskorn et al., 2010; Jaffe, 2014; Goodyear, 2014; Halsey, 2014; Anderson, 2015; Hilkevitch, 2013), the primary bike infrastructure variable tested-density of bike lanes and paths combined-is not significant in any of the models. Moreover, the cycle track density variable in Model 5 associates with higher levels of lawbreaking behavior, but this falls out with both the multilevel model or when accounting for Blocks 1 and 2. This suggests that unmeasured city characteristics may trump infrastructure when it comes to illegal bicyclist behaviors. While this seems to challenge some of the trends found in the existing research, the corridor or intersection-level results found in other papers - such as the presence of a new protected bike lane reducing violations (Anderson, 2015) - may not extend more generally across the city. It is also interesting to note that increased youth bicycling education associates with lower levels of unlawful bicycling behavior; however, this variable again drops out in subsequent models.

\subsection{Multilevel model combining blocks 1, 2, and 3}

Model 8 combines all the variables using a multilevel approach. Our most interesting finding with this approach is that many seemingly important variables lose significance. Overall, the results suggest that unlawful bicyclist behavior is primarily associated with age, gender, bicyclist typology, and due to the importance of the hierarchical results, the unmeasured characteristics of the city where one resides. Variables such as income, education, children, race/ethnicity, and bicyclist mode share are no longer significant when we shift to the multilevel model.

In Table 4, rather than report elasticity measures, we calculate the percent change in the level of unlawful bicyclist behavior based upon changing the level of a single variable and holding all other variables

at their mean. This percent change is based upon the expected score with respect to a reference value close to the mean value of that variable and is mathematically the same as elasticity measures but easier to visualize (Noland \& Quddus, 2004). Regarding gender, for example, the results suggest that, holding all other variables at their mean value, the lawbreaking bicyclist score for a male bicyclist is 2.46 and that for a female is 2.16. Controlling for all other factors, this suggests that male riders have significantly higher levels of unlawful bicycling behavior as compared to females. However, both means still sit squarely in the minor law infringement range. Interestingly, the same can be said for nearly all the other significant variables. Our results suggest that younger males that ride more for utilitarian purposes in a "strong and fearless" manner (Dill \& McNeil, 2013) tend to exhibit the highest levels of illegal bicycling behavior. However, these four factors (i.e., young, male, utilitarian, and a "strong and fearless" bicyclist) — even 
when combined — would not move the respondent into the major infractions category, let alone past the reckless endangerment threshold.

We not only asked respondents to tell us where they live now but also to tell us where they grew up. The first variable (city where they live now) turned out to be significant in the multi-level models. The second factor (where they grew up) was insignificant across all models, indicating that bicyclists tend to behave much more similarly to those in the place where they live now as opposed to those from where they grew up. For instance, people living in Australia tended to have low levels of unlawful bicycling behavior. If an Australian moved to New York, they were more likely to behave like other New Yorkers than had they remained in Australia. Our results cannot yet speak to the suggestion-for this examplethat those more likely to move halfway around the world are also more likely to have higher levels of illegal bicycling behavior, but this finding also seems to hold when looking at people moving within the U.S. and should be considered further in future research.

Table 3: Statistical model results

\begin{tabular}{|c|c|c|c|c|c|c|c|c|c|c|c|c|c|c|c|}
\hline \multirow{3}{*}{\multicolumn{2}{|c|}{$\begin{array}{c} \\
\text { Variable } \\
\text { Intercept } \\
\end{array}$}} & \multirow{2}{*}{\multicolumn{2}{|c|}{$\begin{array}{c}\text { Model 1 } \\
\text { Block 1 } \\
\text { SES Data } \\
\text { Coefficient }\end{array}$}} & \multirow{2}{*}{\multicolumn{2}{|c|}{$\begin{array}{c}\frac{\text { Model } 2}{\text { Block } 2} \\
\text { Bicyclist Type } \\
\text { Coefficient }\end{array}$}} & \multirow{2}{*}{\multicolumn{2}{|c|}{$\begin{array}{c}\frac{\text { Model } 3}{\text { Blocks } 1+2} \\
\text { Coefficient }\end{array}$}} & \multirow{2}{*}{\multicolumn{2}{|c|}{$\begin{array}{c}\text { Model 4 } \\
\text { Blocks 1 + } 2 \\
\text { Multilevel } \\
\text { Coefficient }\end{array}$}} & \multirow[t]{2}{*}{\begin{tabular}{|c|}
$\begin{array}{c}\text { Model } 5 \\
\text { Block } 3 \\
\text { City Character }\end{array}$ \\
Coefficient
\end{tabular}} & \multirow[t]{2}{*}{$\begin{array}{c}\text { Modol } 6 \\
\text { Block } 3 \\
\text { Multilevel } \\
\text { Coefficient }\end{array}$} & \multirow{2}{*}{\multicolumn{2}{|c|}{$\frac{\text { Model } 7}{\text { Blocks } 1+2+3}$}} & \multirow{2}{*}{\multicolumn{2}{|c|}{$\begin{array}{c}\frac{\text { Modlel } 8}{\text { Blocks 1 }} \\
\text { Multilevel } \\
\text { Coefficient }\end{array}$}} \\
\hline & & & & & & & & & & & & & & & \\
\hline & & 1.20000 & $+\infty \times \infty$ & $0.78910 \times$ & $+\infty \infty$ & 0.70320 & $\infty \times \infty$ & $0.67110 \times$ & $\infty+\infty$ & $0.49980 \quad \times \infty \times$ & $0.74240 \quad \times \times x$ & 0.83970 & $\infty \times \infty$ & 0.90360 & $\infty \times \infty$ \\
\hline \multicolumn{16}{|c|}{ Individual Level Variables } \\
\hline \multirow{8}{*}{ 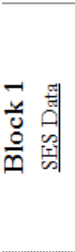 } & Age & -0.00844 & $+\infty \times \infty$ & & & -0.00752 & $+\infty$ & $-0.00500 \approx$ & 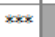 & & & -0.00710 & $\infty \infty x$ & -0.00623 & $\infty \infty x$ \\
\hline & Gender & 0.14050 & $\infty \times \infty$ & & & 0.12000 & $\infty+\infty$ & $0.13830 *$ & $\infty \times \infty$ & & & 0.12280 & $\infty \times \infty$ & 0.12920 & $\infty x$ \\
\hline & Income & -0.00256 & $\infty \times \infty$ & & & -0.00209 & $\infty \infty$ & $-0.00229 \times$ & $\infty \infty x$ & & & - & & - & \\
\hline & Education & 0.03961 & $\infty \times \infty$ & & & 0.03023 & $\infty \times \infty$ & - & & & & - & & - & \\
\hline & Children in Household & -0.07304 & $\star \star$ & & & -0.06197 & $\approx *$ & - & & & & - & & - & \\
\hline & Access to Automobile & - & & & & - & & - & & & & - & & - & \\
\hline & Non-white & 0.24040 & $\infty *$ & & & 0.05383 & $\infty$ & - & & & & - & & - & \\
\hline & Hispanic & - & & & & - & & - & & & & - & & - & \\
\hline \multirow{7}{*}{ 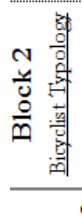 } & Recreational Bicycling & & & -0.02196 & $\infty \infty$ & - & & - & & & & - & & - & \\
\hline & Utilitarian Bicycling & & & $0.04480 \times$ & $\infty \times$ & 0.08460 & $\infty \times \infty$ & $0.08523 \approx$ & $\infty \times \infty$ & & & 0.09614 & $\infty \infty x$ & 0.08507 & $\infty \times \infty$ \\
\hline & Rules of the Road Knowledge & & & - & & - & & - & & & & - & & - & \\
\hline & Taking the Lane Behavior & & & $0.11680 \times$ & $\infty \infty \infty$ & 0.09501 & $\infty \times \infty$ & $0.10010 *$ & $\infty \times \infty$ & & & 0.09509 & $\infty \times \infty$ & 0.09346 & $\infty \times \infty$ \\
\hline & Portland Typology Score & & & $-0.06297 \times$ & $\infty *$ & 0.05400 & $\infty+\infty$ & $0.04851 *$ & $\infty \times \infty$ & & & -0.10360 & $\infty$ & -0.11100 & $\star *$ \\
\hline & Childhood Bicycling & & & - & & - & & - & & & & - & & - & \\
\hline & \multicolumn{15}{|l|}{ City Level Variables } \\
\hline & Intersection Density & & & & & & & & & $0.00150 \quad \infty \times \infty$ & $0.00103 \approx \times$ & 0.00212 & $\infty \times \infty$ & 0.00066 & $\infty \infty x$ \\
\hline 붕 & Bike Mode Share & & & & & & & & & $0.07250 \quad \infty \times x$ & - & -0.01167 & $x+\infty$ & - & \\
\hline$\underline{x}$ & Bike Lanes + Paths Density & & & & & & & & & - & - & - & & - & \\
\hline 훙 & Cycle Track Density & & & & & & & & & $0.36720 \approx \approx$ & - & - & & - & \\
\hline m जी & Bike Fatalities per $10 \mathrm{k}$ Bicyclists & & & & & & & & & - & - & - & & - & \\
\hline r & $\%$ Women Commuters & & & & & & & & & 0.01228 & - & - & & - & \\
\hline & Youth Bicycling Education & & & & & & & & & $-1.99 \mathrm{E}-06$ & - & - & & - & \\
\hline \multicolumn{16}{|c|}{ Interaction of Non-Linear Variables } \\
\hline & (Gender) $\mathrm{x}$ (Children in $\mathrm{HH}$ ) & 0.05779 & $\infty *$ & & & 0.04737 & $* *$ & - & & & & - & & - & \\
\hline & (Education) $\mathrm{x}$ (Non-white) & -0.05831 & $\infty *$ & & & - & & - & & & & - & & - & \\
\hline & (Income) $\mathrm{x}$ (Income) & 0.00001 & $\infty$ & & & 0.00001 & $\infty *$ & $0.00001 \times$ & $\infty$ & & & - & & - & \\
\hline & (Utilitarian) $\mathrm{x}$ (Take the Lane) & & & $-0.01612 x$ & $\infty \infty \infty$ & -0.01024 & $\infty x$ & $-0.01573 \approx$ & $\infty \infty \infty$ & & & -0.01627 & $\infty \infty$ & -0.01488 & $\infty \infty x$ \\
\hline & (Portland Typ) $\mathrm{x}$ (Take the Lane) & & & $-0.01659 \times$ & $x+\infty$ & -0.01631 & $\infty \times \infty$ & $-0.01380 \approx$ & $\infty x$ & & & -0.01477 & $\infty \times \infty$ & -0.01361 & $\approx *$ \\
\hline & (Utilitarian) $\mathrm{x}$ (Utilitarian) & & & $0.01804 *$ & $\infty \times \infty$ & - & & - & & & & - & & - & \\
\hline & (Portland Typ) $\mathrm{x}$ (Portland Typ) & & & $0.01153 \times$ & $\infty+\infty$ & - & & - & & & & 0.01546 & $\infty \times \infty$ & 0.01608 & $\infty \times \infty$ \\
\hline & (Int. Density) x (Bike Mode Share) & & & & & & & & & -0.00055 & - & - & & - & \\
\hline & (Int. Density) x (Int. Density) & & & & & & & & & - & $-6.53 \mathrm{E}-07 \times \infty$ & $-2.87 \mathrm{E}-06$ & $\infty \infty$ & - & \\
\hline \multicolumn{16}{|c|}{ Hierarcbical Effects } \\
\hline & Covariance Parameter Estimate & - & & - & & - & & $0.02138 *$ & $+\infty \infty$ & & 0.02155 \% & & & 0.01607 & 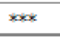 \\
\hline \multicolumn{16}{|c|}{ Model Fit } \\
\hline & Log Pseudo-Likelihood & 15,353 & & 24,607 & & 14,856 & & 13,851 & & 7,603 & 15,753 & 14,375 & & 13,770 & \\
\hline & Generalized Chi-Square & 2,605 & & 4,233 & & 2,490 & & 2,168 & & 1,265 & 2,555 & 2,371 & & 2,173 & \\
\hline & No. of Observations Used & 10,707 & & 16,806 & & 10,571 & & 10,725 & & 5,463 & 11,286 & 10,672 & & 10,682 & \\
\hline$P$ & $* * \mathrm{p}<.05 ; * * * \mathrm{p}<.01$ & & & & & & & & & & & & & & \\
\hline
\end{tabular}


Table 4: Expected change in lawbreaking bicyclist threshold score

\begin{tabular}{|c|c|c|}
\hline \multirow{2}{*}{$\begin{array}{l}\text { Block } 1+2+3 \text { Multileve1 Mode1 } \\
\text { Base Lawbreaking Bigyclist Thresbold Score' }\end{array}$} & \multicolumn{2}{|c|}{$\begin{array}{l}\text { Lawbreaking } \\
\text { Bicyclist } \\
\text { Threshold Score }\end{array}$} \\
\hline & 2.35 & $\%$ Change \\
\hline \multicolumn{3}{|l|}{ Block 1 - SES Differences } \\
\hline \multicolumn{3}{|l|}{ Age } \\
\hline 20 & 2.67 & $13.1 \%$ \\
\hline 30 & 2.51 & $6.4 \%$ \\
\hline 40 (reference value) & 2.36 & - \\
\hline 50 & 2.22 & $-5.9 \%$ \\
\hline 60 & 2.08 & $-11.9 \%$ \\
\hline \multicolumn{3}{|l|}{ Gender } \\
\hline Female & 2.16 & $-12.2 \%$ \\
\hline Male (reference value) & 2.46 & - \\
\hline \multicolumn{3}{|l|}{ Combined Demographic Extremes } \\
\hline Younger \& Male (reference value) & 2.79 & - \\
\hline Older \& Female & 1.91 & $-31.5 \%$ \\
\hline \multicolumn{3}{|l|}{ Block 2 - Bicyclist Typology } \\
\hline \multicolumn{3}{|l|}{ Utilitarian Rider } \\
\hline Never & 2.14 & $-13.4 \%$ \\
\hline Always (reference value) & 2.47 & - \\
\hline \multicolumn{3}{|l|}{ Propensity to "Take the Lane" } \\
\hline Never & 2.27 & $-8.5 \%$ \\
\hline Always (reference value) & 2.48 & - \\
\hline \multicolumn{3}{|l|}{ Rider Typology } \\
\hline No way, no how & 2.71 & $16.3 \%$ \\
\hline Interested but concerned & 2.36 & $1.3 \%$ \\
\hline Enthusiastic and confident (reference value) & 2.33 & - \\
\hline Strong and fearless & 2.63 & $12.9 \%$ \\
\hline \multicolumn{3}{|l|}{ Block 3 - City Characteristics } \\
\hline \multicolumn{3}{|l|}{ Intersection Density } \\
\hline 100 per sq. mi. & 2.21 & $-6.4 \%$ \\
\hline 200 per sq. mi. & 2.36 & - \\
\hline 300 per sq. mi. & 2.52 & $6.8 \%$ \\
\hline
\end{tabular}

\section{Discussion}

When including driving and pedestrian scenario responses—such as how often respondents drive over the speed limit or jaywalk-100\% of our sample population admitted to some form of law-breaking in the transportation system (i.e., everybody is technically a criminal). When disaggregating by mode, $95.87 \%$ of bicyclists, $97.90 \%$ of pedestrians, and nearly all drivers $(99.97 \%)$ selected responses that would be considered illegal ${ }^{3}$. The rationale for why these road users were breaking the law, however, differed by mode. Drivers and pedestrians that break the rules of the road tended to do so to save time ( $77 \%$ and $85 \%$ of drivers and pedestrians, respectively). However, bicyclists report disregarding the rules of road for other reasons. The most prevalent response as to why bicyclists break the rules was "personal safety" with more than $71 \%$ of respondents citing that as a reason. Saving energy came in second for bicyclists (56\%) followed by saving time (50\%). Increasing one's visibility was the fourth most cited response (47\%) for bicyclists breaking the law. While the overwhelming majority of bicyclists break the rules, the open response answers suggest that most do so in situations where little harm would come to themselves or others and are often motivated by concerns for their own safety because they feel like an afterthought in a car-dominated transportation system.

Why might bicyclists feel this way? Even in the most bike-friendly U.S. cities, bicycling often

${ }^{3}$ This assumes conventional traffic laws. 
remains marginalized. For instance, Boulder, Colorado—renowned for its bicycling infrastructure-has 305 center-line miles of motorized roadways but only 38 miles of bike lanes (12\% of total) and 58 miles of non-motorized, multi-use pathways (19\% of roadway total). In terms of transportation budget, $17 \%$ went to bicycling-related projects over a recent 20 -year period (Henao et al., 2015). While modest compared to car-related spending, Boulder is well above the national average where only $1.6 \%$ of federal transportation funds goes towards bicycling and walking combined despite national journey-to-work active transportation mode shares more than double that percentage (Milne \& Melin, 2014). The fact that the transportation field continues to comingle bicycling and walking despite their distinct infrastructure needs and safety issues further suggests a disregard for bicycling (Vivanco, 2013). This issue also extends to how bicyclists are perceived and characterized. The media, for instance, often portrays bicyclists as abnormal such as in Pee-wee's Big Adventure and The 40-Year Old Virgin (Furness, 2010) while researchers have found survey respondents more than willing to describe bicyclists as "over-zealous eco-warriors," "bike nuts," and even "a fucking waste of space" (Aldred, 2010; Basford et al., 2002; Fincham, 2007; Horton, 2006; Aldred, 2013; Aldred \& Jungnickel, 2010).

Such a range of challenges prevents many from bicycling in the first place. This can result in a lack of shared mobility experiences. In other words, if few drivers also bicycle regularly, there may be an associated lack of empathy regarding the often difficult and dangerous circumstances in which bicyclists ride, further exasperating negative perceptions towards bicyclists (Basford et al., 2002). How can we fix this problem? Typically, we attempt to do so by increasing bicycling rates with outreach events like Bike to Work Day (Piatkowski et al., 2015). Paradoxically, such efforts can further marginalize bicyclists. Like Black History Month and departments of Women's Studies, they can seem more like institutional consolation prizes for disenfranchised groups, especially when not accompanied by adequate funding or infrastructure. Yet, positive perceptions of bicycling as a healthy and environmental-friendly activity continue to grow. The new reality in some cities is that bicycling is an activity with relatively broad participation and growing mode shares.

This combination of diverging factors suggests that the prevalence of unlawful bicycling behaviors and/or the perception of such behaviors may differ from place to place. Our analysis confirms this premise in that the unmeasured aspects of the city where one lives outweigh most individual bicyclist characteristics such as where one grew up, race/ethnicity, whether one has kids, and income. In searching for further understanding as to why the city one lives in may impact bicycling behavior as much, if not more, than individual characteristics, we came across several well-regarded papers by researchers such as Granovetter that have investigated social processes such riots or the forming of public opinion (Granovetter 1978; Granovetter \& Strong, 1988; Gladwell, 2015). This research strand suggests that various thresholds of collective behavior drive many decisions. In other words, collective action derives via individuals with differing thresholds. The first person to run a red light while on a bicycle might have a high lawbreaking bicyclist threshold score; the second person might not have run the red on their own accord but would do so once they see somebody else; the third and fourth people to run the red perhaps needed to see a couple other people doing so before them. The last person to do so might be a law-abiding member of society in every aspect of their life, but they may also run the red light once they see that everyone around them is doing the same thing.

At this point, the magnitude and direction of the city-level effects is unclear, but our results suggest that the overall context, norms, and social processes of a city play a meaningful role in bicycling behaviors. The importance of such contextual place-based factors has similarly been seen in the driver behavior literature (De Pelsmacker \& Janssens, 2007), and the process of acculturation may also be playing a role in these results (Sam \& Berry, 2006). Additional research is needed to shed light on what exactly these unmeasured contextual factors may be. 


\section{Conclusions}

This research explores the behaviors of unlawful bicyclists, the factors that associate with such behaviors, and their underlying rationales. Proven effective for reaching hard-to-reach populations, we employed a snowball-sampling framework and an online, scenario-based survey that received nearly 18,000 responses. Via multi-level statistical analyses, our results suggest that the unmeasured social and contextual norms of a city tend to outweigh individual bicyclist characteristics such as race/ethnicity and income. While younger people, males, utilitarian bicyclists, and those more comfortable riding in mixed traffic tend to exhibit higher levels of unlawful bicycling behavior, the overwhelming majority of bicyclists are not reckless, even when combining the high-risk factors.

When it comes to rule-breaking bicyclists, one popular opinion is that if bicyclists want to be taken seriously as road users, they need to obey the rules of the road like everyone else. Our survey results and the literature review both suggest that drivers break the rules of the road just as much, if not more, than bicyclists. The other common argument is that cities need to step up bicycle law enforcement to improve safety. While bicyclists are certainly not immune from causing harm, the literature suggests lower societal costs and safety risks associated with lawbreaking bicycling as compared to lawbreaking driving. Drivers speed, roll through stop signs, park in bike lanes, and run lights that have just turned red while still considering themselves to be law-abiding citizens. Despite research showing a causal link between such driving behaviors and increased crash rates, injuries, and fatalities, society continues to see these behaviors as rational decisions within our transportation system, other than in the relative minority of places that take Vision Zero as more than a buzzword. Our results suggest that bicyclists seem to be making the same rational choices. Curbing patently reckless bicycling behavior in our transportation system would certainly be a good thing; however, our results suggest that the overwhelming majority of unlawful bicyclists are behaving rationally and not recklessly. If Vision Zero is the goal, then we may want to prioritize enforcement efforts on road users with greater impact on actual safety outcomes.

While snowball samples have proven effective for comparable populations, future research should look to evaluate the results of our convenience-based sample against other approaches. This includes probability-based sample populations even though they can also be criticized for bias or self-selection (Sadler et al., 2010; Van Meter, 1990; Guttman, 1984). Our research also assumes that respondents are being truthful and realistic about their illegal behaviors. While respondents may have under- or overreported their reckless behavior, online surveys have proven beneficial when it comes to enticing survey respondents to disclose illegal activities (Khazaal et al., 2014; Ramo \& Prochaska, 2012; Van Selm \& Jankowski, 2006); nevertheless, this assumption remains a limitation. This work is additionally limited by the possible exclusion of potentially relevant populations (e.g., low-income, immigrants, those legally prohibited from driving) that could be less likely to use the internet or complete a bicycling behavior survey (Lugo, 2013; Zavestoski and Agyeman, 2015). Minority populations may also report dramatically different responses given the history of disproportionate enforcement of minor traffic violations by police in some communities (Lundman and Kaufman, 2003; Warren et al., 2006; Harris, 1999; Roh and Robinson, 2009). Unfortunately, addressing these disparities with regard to bicycle behavior is beyond the scope of this paper.

It would also be interesting to consider within-individual differences in illegal behaviors by mode. In other words, do lawbreaking bicyclists behave similarly when walking or driving? How might this depend on the rationale stated for breaking bicycling laws? Future research could combine these results with additional observational data, built environment data, street design factors, local context and bike culture data, and enforcement information. Such data would help facilitate studies at smaller levels of geography than we were able to cover in this paper and perhaps a more nuanced understanding of the 
issues at hand.

As rates of bicycling continue to increase (ACS, 2014), the new normal on our city streets means more bicyclists. Yet, our results suggest that far fewer bicyclists than expected fit the stereotype of the rude and reckless bike messenger. The current iteration of our transportation system was not designed with bicycles in mind, and most bicyclists seem focused on surviving in a system designed for a very different mode of transportation (Marohn, 2014). The word "scofflaw" emerged after a 1924 Boston Herald contest to describe those that disobeyed Prohibition laws but for rational reasons that did not necessarily break social norms (Burns \& Coyote, 2011). Our results suggest that most bicyclists can also be described as scofflaws. This is not intended as a pejorative. Rather, scofflaw bicyclists tend to be rational individuals trying to function safely and efficiently, even if it means they are doing so illegally, given the social norms of where they live and the transportation system put in front of them.

\section{Acknowledgments}

Thank you to the Mountain Plains Consortium and U.S. DOT for funding related to this work, the faculty and students of the Active Communities/Transportation Research Group and CU Denver Transportation Research Center for piloting the survey, and to the many of thousands of people from around the world that took the time to respond. You are all very much appreciated.

Please note that our data sharing agreement with Alliance for Biking and Walking as well as the confidentiality requirements of our IRB protocol preclude us from publicly sharing the raw data. 


\section{References}

AAA. (2010). Traffic safety culture index. Washington, D.C.: AAA Foundation for Traffic Safety.

ACS. (2014). American community survey (ACS) 5-year data (2010-2014). Edited by U.S. Census Bureau. Washington, D.C.

Aldred, R. (2010). On the outside: Constructing cycling citizenship. Social \& Cultural Geography, 11(1), 35-52. doi: 10.1080/14649360903414593

Aldred, R. (2013). Incompetent or too competent? Negotiating everyday cycling identities in a motor dominated society. Mobilities, 8(2), 252-271. doi: 10.1080/17450101.2012.696342

Aldred, R., \& Jungnickel, K. (2010). I didn't feel like a proper cyclist: Managing problematic and provisional cycling identities. Paper presented at the Bicycle Politics Symposium and Workshop, Lancaster, UK, September 16.

Anderson, M. (2013, June 25). 94\% of bike riders wait at red lights, study finds [web log post]. BikePortland.org. Retrieved from http://bikeportland.org/2013/06/25/94-of-bikes-wait-at-red-lightsstudy-finds-89025

Anderson, M. (2015, May 7). Honolulu installs protected bike lane, sees massive drop in sidewalk biking [web log post]. People for Bikes. Retrieved from www.peopleforbikes.org/blog/entry/honoluluinstalls-protected-bike-lane-sees-massive-drop-in-sidewalk-biking.

APR. (1998). Campagne d'affichage Piétons [Poster Campaign Pedestrians]. Paris, France: Association Prévention Routière.

Atkinson, R., \& Flint, J. (2001). Accessing hard to reach populations for research: Snowball research strategies. Social Research Update, 33(1), 1-4.

Avico, U., Kaplan, C., Korczak, D., \& Van Meter, K. (1988). Cocaine epidemiology in three European Community cities: A pilot study using a snowball sampling methodology. Brussels: European Communities Health Directorate.

Bacchieri, G., Barros, A. J. D., dos Santos, J. V., \& Gigante, D. P. (2010). Cycling to work in Brazil: Users profile, risk behaviors, and traffic accident occurrence. Accident Analysis and Prevention, 42(4), 1025-1030. doi: 10.1016/j.aap.2009.12.009

Badger, E. (2015, January 9). Let's talk seriously about why cyclists break traffic laws [Web log post]. The Washington Post Wonkblog. Retrieved from https:/www.washingtonpost.com/news/ wonk/wp/2015/01/09/lets-talk-seriously-about-why-cyclists-break-traffic-laws/?utm_term=. e52930eee061

Baltar, F., \& Brunet, I. (2012). Social research 2.0: Virtual snowball sampling method using Facebook. Internet Research, 22(1), 57-74. doi: 10.1108/10662241211199960

Basford, L., Reid, S., Lester, T., Thomson, J., \& Tolmie, A. (2002). Drivers' perceptions of cyclists. London, UK: Department for Transport.

Beck, K. (2007). Enforce bicycle riding laws. Law and Order 55 (6):82-87.

Becker, G. S. (1974). Crime and punishment: An cconomic approach. In G. S. Becker and W. M. Landes (Eds.), Essays in the Economics of Crime and Punishment (pp. 1-54). Cambridge, MA: The National Bureau of Economic Research.

Benfield, J. A., \& Szlemko, W. J. (2006). Internet-based data collection: promises and realities. Journal of Research Practice, 2 (2).

Berk, R. A., \& Ray, S. C. (1982). Selection biases in sociological data. Social Science Research, 11(4), 352-398. doi: 10.1016/0049-089x(82)90003-5

Biernacki, P., \& Waldorf, D. (1981). Snowball sampling: Problems and techniques of chain referral sampling. Sociological methods \& research, 10(2), 141-163.

Brennan, M., Rae, N., \& Parackal, M. (1999). Survey-based experimental research via the web: Some 
observations. Marketing Bulletin, 10, 83-92.

Burns, K., \& Novick, L. (directors/producers) (2011). Prohibition [documentary film series]. USA: Florentine Films and WETA.

Burton, N. W., Haynes, M., Wilson, L. A. M., Giles-Corti, B., Oldenburg, B. F., Brown, W. J., Giskes, K., \& Turrell, G. (2009). HABITAT: A longitudinal multilevel study of physical activity change in mid-aged adults. BMC Public Health, 9, 76-87. doi: 10.1186/1471-2458-9-76

Chappell, B. (2015, July 9). Cyclists can ignore some traffic lights, Paris announces. National Public Radio. Retrieved from http://www.npr.org

Chen, I. G., Elliott, M. R., Durbin, D. R., \& Winston, F. K. (2005). Teen drivers and the risk of injury to child passengers in motor vehicle crashes. Injury Prevention, 11(1), 12-17. doi: 10.1136/ ip.2004.007617

Chong, S., Poulos, R., Olivier, J., Watson, W. L., \& Grzebieta, R. (2010). Relative injury severity among vulnerable non-motorised road users: Comparative analysis of injury arising from bicyclemotor vehicle and bicycle-pedestrian collisions. Accident Analysis and Prevention, 42(1), 290-296. doi: 10.1016/j.aap.2009.08.006

Codina, E., Kaplan, C. D., Yin, Z., Valdez, A., \& Mata, A. (1999). Estimating the extent of injecting heroin use in Laredo, Texas. Journal of Border Health, 4, 3-11.

Coleman, J. S. (1958). Relational analysis: The study of social organization with survey methods. $\mathrm{Hu}$ man Organization, 17, 28-36.

Conner, M., Smith, N., \& McMillan, B. (2003). Examining normative pressure in the theory of planned behaviour: Impact of gender and passengers on intentions to break the speed limit. Current Psychology, 22(3), 252-263. doi: 10.1007/s12144-003-1020-8

Constantinou, E., Panayiotou, G., Konstantinou, N., Loutsiou-Ladd, A., \& Kapardis, A. (2011). Risky and aggressive driving in young adults: Personality matters. Accident Analysis and Prevention, 43 (4), 1323-1331. doi: 10.1016/j.aap.2011.02.002

Corbett, C., \& Simon, F. (1992). Unlawful driving behavior: A criminological perspective. Crowthorne, England: Transport Research Laboratory.

Daff, M., \& Barton, T. (2005). Marking Melbourne's arterial roads to assist cyclists. ITE 2005 Annual Meeting and Exhibit Compendium of Technical Papers, Melborne, Australia.

Davis, A. J. (1997). Race, Cops, and Traffic Stops. University of Miami Law Review 51 (425).

De Pelsmacker, P., \& Janssens, W. (2007). The effect of norms, attitudes and habits on speeding behavior: Scale development and model building and estimation. Accident Analysis and Prevention, 39(1), 6-15. doi: 10.1016/j.aap.2006.05.011

Dill, J., \& McNeil, N. (2013). Four types of cyclists? Examination of typology for better understanding of bicycling behavior and potential. Transportation Research Record, 2387,129-138. doi: $10.3141 / 2387-15$

Dissanayake, S., \& Lu, J. (2002). Analysis of severity of young driver crashes-Sequential binary logistic regression modeling. Statistical Methodology: Applications to Design, Data Analysis, and Evaluation, 1784,108-114. doi: 10.3141/1784-14

Dusek, G. A., Yurova, Y. V. , \& Ruppel, C. P. (2015). Using social media and targeted snowball sampling to survey a hard-to-reach population: A case study. International Journal of Doctoral Studies, 10, 279-299. Retrieved from http://ijds.org/Volume10/IJDSv10p279-299Dusek0717.pdf

Elinson, Z. (2013, April 13). Bay Area drivers who kill pedestrians rarely face punishment, analysis finds. The Center for Investigative Reporting.

Elvik, R. (2005). Speed and road safety: Synthesis of evidence from evaluation studies. Transportation Research Record: Journal of the Transportation Research Board, 1908, 59-69. doi: 10.3141/1908-08 
Elvik, R. (2012). Speed limits, enforcement, and health consequences. Annual Review of Public Health, 33, 225-238. doi: 10.1146/annurev-publhealth-031811-124634

Engel, R. S., \& Calnon, J. M. (2004). Examining the influence of drivers' characteristics during traffic stops with police: Results from a national survey. Justice Quarterly, 21(1).

Evans, J. R., \& Mathur, A. (2005). The value of online surveys, 15(2), 195-219. doi: http://dx.doi. org/10.1108/10662240510590360

Ewing, R., and Cervero, R. (2010). Travel and the built environment. Journal of the American Planning Association, 76(3), 265-294.

Ewing, R., Schmid, T., Killingsworth, R., Zlot, A., \& Raudenbush, S. (2003). Relationship between urban sprawl and physical activity, obesity, and morbidity. American Journal of Health Promotion, $18(1), 118-126$.

Fajans, J., \& Curry, M. (2001). Why bicyclists hate stop signs. Access Magazine. Retrieved from www. accessmagazine.org

Fincham, B. (2006). Bicycle messengers and the road to freedom. Sociological Review 54, 208-222. doi: $10.1111 /$ j.1467-954X.2006.00645.x

Fincham, B. (2007). 'Generally speaking people are in it for the cycling and the beer:' Bicycle couriers, subculture, and enjoyment. Sociological Review, 55(2), 189-202. doi: 10.1111/j.1467954X.2007.00701.x

Fitzgerald, J. L. (1996). Hidden populations and the gaze of power. Journal of Drug Issues, 26, 5-21. Fitzpatrick, K., Carlson, P., Brewer, M. A., Wooldridge, M. D., \& Miaou, S.-P. (2004). Design speed, operating speed, and posted speed practices (NCHRP 504). Washington D.C.: National Cooperative Highway Research Program.

Fleiter, J. J., Lennon, A., \& Watson, B. (2007, October). Choosing not to speed: A qualitative exploration of differences in perceptions about speed limit compliance and related issues. Presented at the meeting of the Australasian Road Safety Research Policing and Education Conference, Melbourne, Australia.

Fleiter, J. J., Lennon, A., and Watson, B. (2010). How do other people influence your driving speed? Exploring the 'who' and the 'how' of social influences on speeding from a qualitative perspective. Transportation Research Part F: Traffic Psychology and Behaviour, 13(1), 49-62. doi: 10.1016/j. trf.2009.10.002

Forsyth, E., \& Silcock, D. T. (1987). The association of traffic offences with road accidents in the Northumbria Police Area. Newcastle-upon-Tyne, UK: Newcastle University.

Furness, Z. (2010). One less car: Bicycling and the politics of automobility. Philadelphia, PA: Temple University.

Gibby, A. R., Stites, J. L., Thurgood, G. S., \& Ferrara, T. C. (1994). Evaluation of marked and unmarked crosswalks at intersections in California. Washington, D.C.: Federal Highway Administration

Gladwell, M. (2015, October 17-19). Thresholds of violence: How school shootings catch on. The New Yorker: Annals of Publc Safety. Paper presented at the Australasian Road Safety Research, Policing and Education Conference. Retrieved from http://acrs.org.au/publications/conference-papers/

Goodyear, S. (2013, May 13). Cyclists aren't 'special,' and they shouldn't play by their own rules [Web $\log$ post]. CityLab. Retrieved from www.citylab.com/

Goodyear, S. (2014, February 4). New York's cyclists are getting better at following the rules [Web log post]. CityLab. Retrived from www.citylab.com/

Gosling, S. D., Vazire, S., Srivastava, S., \& John, O. P. (2004). Should we trust web-based studies? A comparative analysis of six preconceptions about Internet questionnaires. American Psychologist, 59(2), 93-104. doi: 10.1037/0003-066x.59.2.93 
Götschi, T., Krizek, K. J., McGinnis, L., Lucke, J., \& Barbeau, J. (2011). Nonmotorized transportation pilot program evaluation study, phase 2. Washington, D.C.: Federal Highway Administration

Grabar, H. (2013, May). Why we should never fine cyclists [Web log post]. CityLab. Retrived from www.citylab.com/

Granovetter, M. (1978). Threshold models of collective behavior. American Journal of Sociology, 83(6),1420-1443. doi: 10.1086/226707

Granovetter, M., \& Strong, R. (1988). Threshold models of diversity: Chinese restaurants, residential segregation, and the spiral of silence. Sociological Methodology, 18, 69-104. doi: 10.2307/271045

Green, F. K. (2003). Red light running. Vermont South, Australia: ARRB Transport Research Ltd.

Griffiths, P., Gossop, M., Powis, B., \& Strang, J. (1993). Reaching hidden populations of drug users by privileged access interviewers: Methodological and practical issues. Addiction, 88, 1617-1626.

Groger, L., Mayberry, P. S., \& Straker, J. K. (1999). What we didn't learn because of who would not talk to us. Qualitative Health Research, 9(6), 829-835. doi: 10.1177/104973299129122180

Guttman, L. (1984). What is not what in statistics. Statistical inference revisited. Bulletin of Sociological Methodology, 4, 3-35.

Haglund, M., \& Lars Åberg, L. (2000). Speed choice in relation to speed limit and influences from other drivers. Transportation Research Part F: Traffic Psychology and Behaviour, 3(1), 39-51. doi: 10.1016/S1369-8478(00)00014-0

Halsey, A. (2014, August 7). With bike lanes, fewer riders on sidewalk, study says. Washington Post.

Handcock, M. S., \& Gile, K. J. (2011). Comment: On the concept of snowball sampling. Sociological Methodology, 41 (1), 367-371. doi: 10.1111/j.1467-9531.2011.01243.x

Harris, D. A. (1999). Driving while black: Racial profiling on our nation's highways. New York: American Civil Liberties Union.

Harzing, A. W. (1997). Response rates in international mail surveys: Results of a 22-country study. International Business Review, 6(6), 641-665.

Hatfield, J., \& Fernandes, R. (2009). The role of risk-propensity in the risky driving of younger drivers. Accident Analysis and Prevention, 41(1), 25-35. doi: 10.1016/j.aap.2008.08.023

Healy, M. (2001). Multilevel data and their analysis. In Multilevel modelling of health statistics, edited by A.H. Leyland \& H. Goldstein. New York: John Wiley and Sons, Inc.

Heckathorn, D. D., \& Jeffri, J. (2001). Finding the beat: Using respondent-driven sampling to study jazz musicians. Poetics, 28 (4), 307-329. doi: 10.1016/S0304-422x(01)80006-1

Henao, A., Piatkowski, D., Luckey, K. S., Nordback, K., Marshall, W. E., \& Krizek, K. J. (2015). Sustainable transportation infrastructure investments and mode share changes: A 20-year background of Boulder, Colorado. Transport Policy, 37, 64-71. doi: 10.1016/j.tranpol.2014.09.012

Hendricks, V. M., Blanken, P., \& Adriaans, N. (1992). Snowball sampling: A pilot study on cocaine use. Rotterdam: IVO.

Herslund, M. B., \& Jorgensen, N. O. (2003). Looked-but-failed-to-see-errors in traffic. Accident Analysis and Prevention 35,(6), 885-891. doi: 10.1016/S0001-4575(02)00095-7

Hilkevitch, J. (2013, June 10). City says Dearborn bike signals keeping cyclists in line. Chicago Tribune.

Holson, L. M. (2015, October 20). San Francisco May Let Bicyclists Yield at Stop Signs. The New York Times. Retrieved from http://www.nytimes.com/2015/10/21/us/san-francisco-may-let-bicyclists-yield-at-stop-signs.html?_r=0

Horton, D. (2006). Environmentalism and the Bicycle. Environmental Politics, 15(1), 41-58.

IIHS. (2007). Status report. Ruckersville, VA: Insurance Institute for Highway Safety.

Inciardi, J. A., \& Russe, B. R. (1977). Professional thieves and drugs. International Journal of the Ad- 
dictions, 12(8):1087-1095.

Internet Live Stats. (2016). Number of Internet users worldwide. Real Time Statistics Project. Accessed May 25 from www.internetlivestats.com/internet-users/

Iversen, H. (2004). Risk-taking attitudes and risky driving behaviour. Transportation Research Part FTraffic Psychology and Behaviour, 7(3), 135-150. doi: 10.1016/j.trf.2003.11.003

Jaffe, E. (2014, August 14). Tired of cyclists riding on the sidewalk? Build more bike lanes [Web log post]. CityLab.

Johnson, M., Charlton, J., \& Oxley, J. (2008). Cyclists and red lights—a study of the behaviour of commuter cyclist in Melbourne. Paper presented at the Australasian Road Safety Research, Policing and Education Conference, Adelaide, Australia.

Johnson, M., Charlton, J., Oxley, J., \& Newstead, S. (2013). Why do cyclists infringe at red lights? An investigation of Australian cyclists' reasons for red light infringement. Accident Analysis and Prevention, 50, 840-847. doi: 10.1016/j.aap.2012.07.008

Johnson, M., Newstead, S., Charlton, J., \& Oxley, J. (2011). Riding through red lights: The rate, characteristics and risk factors of non-compliant urban commuter cyclists. Accident Analysis and Prevention, 43(1), 323-328. doi: 10.1016/j.aap.2010.08.030

Johnston, L., \& Sabin, K. (2010). Sampling hard-to-reach populations with respondent driven sampling. Methodological Innovations Online, 5, 38-48. doi: 10.4256/mio.2010.0017

Joshi, M. S., Senior, V., \& Smith, G. P. (2001). A diary study of the risk perceptions of road users. Health Risk \& Society, 3(3), 261-279. doi: 10.1080/13698570120079877

Jung, S. Y., Qin, X., \& Noyce, D. A. (2010). Rainfall effect on single-vehicle crash severities using polychotomous response models. Accident Analysis and Prevention, 42(1), 213-224. doi: 10.1016/j. aap.2009.07.020

Kalton, G., \& Anderson, D. W. (1986). Sampling rare populations. Journal of the Royal Statistical Society, 149(1), 65-82.

Kanellaidis, G., Golias, J., \& Zarifopoulos, K. (1995). A survey of drivers attitudes toward speed limit violations. Journal of Safety Research, 26(1), 31-40. doi: 10.1016/0022-4375(94)00025-5

Kaplan, N. M. (1987). Antihypertensive drugs-How different classes can impact patients coronary heart-disease risk profile and quality-of-life. American Journal of Medicine, 82(1a), 9-14. doi: 10.1016/0002-9343(87)90137-9

Katz, E., \& Lazarsfeld, P. F. (1955). Personal influence: The part played by people in the flow of mass communications. New York: Free Press.

Kelly, J. (2014, July 14). Cyclists explain why they sometimes ride on the sidewalk in downtown D.C. Washington Post. Retrieved from https://www.washingtonpost.com

Kemper, E. A., Springfield, S., \& Teddlie, C. (2003). Mixed methods sampling strategies in social science research. In A. Tashakkori \& C. Teddlie (Eds.), Handbook of mixed methods in social \& behavioral research (pp. 273-296). Thousands Oaks, California: SAGE Publications.

Khazaal, Y., van Singer, M., Chatton, A., Achab, S., Zullino, D., Rothen, S., Khan, R., Billieux, J., \& Thorens, G. (2014). Does self-selection affect samples' representativeness in online surveys? An investigation in online video game research. Journal of Medical Internet Research, 16(7), e164-e164. doi: $10.2196 /$ jmir.2759

Kidder, J. L. (2005). Style and action-A decoding of bike messenger symbols. Journal of Contemporary Ethnography, 34(3), 344-367. doi: 10.1177/0891241605274734

Krizek, K. J., Handy, S. L., \& Forsyth, A. (2009). Explaining changes in walking and bicycling behavior: Challenges for transportation research. Environment and Planning B-Planning \& Design, 36(4), 725-740. doi: 10.1068/b34023 
Lavetti, E., \& McComb, S. (2014). Examining bicycle safety on a college campus: Observations and rationale for unsafe cycling. Proceedings of the Human Factors and Ergonomics Society 58th Annual Meeting, Chicago, IL.

Lawson, S. D. (1991). Red-light running: Accidents and surveillance cameras. Basingstoke, England: AA Foundation for Road Safety Research and Birmingham City Council.

Li, F. Z., Fisher, K. J., Brownson, R. C., \& Bosworth, M. (2005). Multilevel modelling of built environment characteristics related to neighbourhood walking activity in older adults. Journal of Epidemiology and Community Health, 59(7), 558-564. doi: 10.1136/jech.2004.028399

Loskorn, J., Mills, A., Brady, J., Duthie, J., \& Machemehl, R. (2010). Effects of bicycle boxes on bicyclist and motorist behavior at intersections. Austin, Texas: University of Texas at Austin.

Lugo, A. E. (2013). CicLAvia and human infrastructure in Los Angeles: ethnographic experiments in equitable bike planning. Journal of Transport Geography, 30, 202-207. doi: 10.1016/j.jtrangeo.2013.04.010

Lundman, R. J., \& Kaufman, R. L. (2003). Driving while black: Effects of race, ethnicity, and gender on citizen self-reports of traffic stops and police actions. Criminology. doi: 10.1111/J.17459125.2003.Tb00986.X

Machin, M. A., \& Sankey, K. S. (2008). Relationships between young drivers' personality characteristics, risk perceptions, and driving behaviour. Accident Analysis and Prevention, 40(2), 541-547. doi: 10.1016/j.aap.2007.08.010

Marohn, C. (2014. May 19). Follow the rules, bikers [Web blog post]. Strong Towns. Retrieved from https://www.strongtowns.org/journal/2016/4/21/follow-the-rules-bikers

Marshall, W. E., \& Garrick, N. W. (2010). Considering the role of the street network in road safety: A case study of 24 California cities. Urban Design International Journal, 15(3), 133-147.

Marshall, W. E., \& Garrick, N. W. (2010). The effect of street network design on walking and biking. Transportation Research Record, 2198, 103-115.

Marshall, W. E., \& Garrick, N. W. (2011a). Does street network design affect traffic safety? Accident Analysis and Prevention 43(3), 769-781.

Marshall, W. E., \& Garrick, N. W. (2011b). Evidence on why bike-friendly cities are safer for all road users. Journal of Environmental Practice, 13(1), 16-27.

Marshall, W. E., \& Garrick, N. W. (2012). Community design \& how much we drive. Journal of Transport and Land Use, 5(2), 5-21. doi: 10.5198/jtlu.v5i2.301

Marshall, W. E., Piatkowski, D., \& Garrick, N.W. (2015). Community design, street networks, and public health Journal of Transport \& Health, 1(4), 326-340. doi: 10.1016/j.jth.2014.06.002i

McLean, K., \& Rojek, J. (2016). Traffic stops, race, and measurement. In B. M. Huebner \& T. S. Bynum (Eds.), The Handbook of Measurement Issues in Criminology and Criminal Justice. West Sussex, UK: John Wiley \& Sons, Inc.

McNamara, R. P. (1994). The Times Square hustler: Male prostitution in New York City. Westport, Connecticut: Praeger.

Medlin, C., Roy, S., \& Chai, T. H. (1999). World Wide Web versus mail surveys: A comparison and report. Paper presented at ANZMAC99 Conference: Marketing in the Third Millennium, Sydney, Australia.

Meggs, J. N. (2010). Bicycle safety and choice: Compounded public cobenefits of the Idaho law relaxing stop requirements for cycling. Berkeley, California: University of California Berkeley.

Meggs, J. N. (2011, September 29). The Idaho law: Allowing safer choice and happier travel [Web log post]. The Meggs Report. Retrived from https://meggsreport.wordpress.com/2011/09/29/the-idaholaw-allowing-safer-choice-and-happier-travel/ 
Mehta, R., \& Sivadas, E. (1995). Comparing response rates and response content in mail versus electronic mail surveys. Journal of the Market Research Society, 37(4), 429-439.

Merton, R. K. (1949). Patterns of influence: A study of interpersonal influence and communications behavior in a local community. In P. F. Lazarfeld and F. Stanton (Eds.), Communications research, (pp. 180-219). New York: Harper.

Milloy, C. (2014, July 8). Bicyclist bullies try to rule the road in D.C. The Washington Post.

Milne, A., \& Melin, M. (2014). Bicycling and walking in the United States: 2014 benchmarking report. Washington, D.C.: Alliance for Biking \& Walking.

Noland, R., \& Quddus, M. (2004). A spatially disaggregate analysis of road casualties in England. Accident Analysis and Prevention, 36(6), 973-984.

O'Brien, S., Tay, R., \& Watson, B. (2002). An exploration of Australian driving anger. Proceedings of the Road Safety Research, Policing and Education Conference, Adelaide, South Australia.

O’Rourke, P. J. (2011, April 2). Dear urban cyclists: Go play in traffic. The Wall Street Journal.

ONISR. (2013). La sécurité routière en France: Bilan de l'accidentologie, 2012 (Road Safety in France: 2012 record of road fatalities). Paris, France: Observatoire national interministériel de la sécurité routière (The interministerial national observatory for road safety).

Ouimet, M. C., Morton, B. G. S., Noelcke, E. A., Williams, A. F., Leaf, W. A., Preusser, D. F., \& Hartos, J. L. (2008). Perceived risk and other predictors and correlates of teenagers' safety belt use during the first year of licensure. Traffc Injury Prevention, 9(1), 1-10. doi: $10.1080 / 15389580701638793$

Patrick, J. (1973). A Glasgow gang observed. London: Eyre Methuen.

Penrod, J., Preston, D. B., Cain, R. E., \& Starks, M.T. (2003). A discussion of chain referral as a method of sampling hard-to-reach populations. Journal of Transcultural Nursing, 14(2), 100-107. doi: $10.1177 / 1043659602250614$

Piatkowski, D., Bronson, R., Marshall, W. E., \& Krizek, K. J. (2015). Measuring the impacts of bike-to-work day events and identifying barriers to increased commuter cycling. Journal of Urban Planning and Development, 141(4). doi: 10.1061/(ASCE)UP.1943-5444.0000239

Pollok, M., \& Schlitz, M. A. (1988, June). Does voluntary testing matter? How it influences homosexual safer sex. Paper presented at the Fourth International Conference on AIDS, Stockholm, Sweden.

RAC. (2007). Motoring offenses: 1998-2006. Walsall, England: Royal Automobile Club.

Radenbush, S. W., \& Bruk, A. (2002). Hierarchical linear models: Applications and data analysis methods 2nd ed. Thousand Oaks, CA: Sage Publications.

Ramo, D. E., \& Prochaska, J. J. (2012). Broad reach and targeted recruitment Using Facebook for an online survey of young adult substance use. Journal of Medical Internet Research, 14(1). doi: 10.2196/jmir.1878

Retting, R. A., Ulmer, R. G., \& Williams, A. F. (1999). Prevalence and characteristics of red light running crashes in the United States. Accident Analysis and Prevention, 31(6), 687-694. doi: 10.1016/ S0001-4575(99)00029-9

Retting, R. A., Williams, A. F., Farmer, C. M., \& Feldman, A. F. (1999). Evaluation of red light camera enforcement in Oxnard, California. Accident Analysis and Prevention, 31(3), 169-174. doi: 10.1016/S0001-4575(98)00059-1

Retting, R. A., Williams, A. F., \& Greene, M. A. (1998). Red-light running and sensible countermeasures—Summary of research findings. Traffic Safety, 1640, 23-26. doi: 10.3141/1640-04

Retting, R. A., Williams, A. F., Preusser, D. F., \& Weinstein, H. B. (1995). Classifying urban crashes for countermeasure eevelopment. Accident Analysis and Prevention, 27(3), 283-294. doi: 10.1016/0001-4575(94)00068-W 
Rhodes, N., \& Pivik, K. (2011). Age and gender differences in risky driving: The roles of positive affect and risk perception. Accident Analysis and Prevention, 43(3), 923-931. doi: 10.1016/j. aap.2010.11.015

Rinella, V. J. (1967). Police brutality and racial prejudice: A first close look. Journal of Urban Law Editors, 45,773 .

Ritter, P., Lorig, K., Laurent, D., \& Matthews, K. (2004). Internet versus mailed questionnaires: A randomized comparison. Journal of Medical Internet Research, 6(3), 19-25. doi: 10.2196/ jmir.6.3.e29

Roh, S., \& Robinson, M. (2009). AgGeographic approach to racial profiling: The microanalysis and macroanalysis of racial disparity in traffic stops. Police Quarterly, 12(2), 137-169.

Rundle, A., Roux, A. V. D., Freeman, L. M., Miller, D., Neckerman, K. M., \& Weiss, C. C. (2007). The urban built environment and obesity in New York City: A multilevel analysis. American Journal of Health Promotion, 21(4), 326-334.

Sadler, G. R., Lee, H.-C., Lim, R. S.-H., \& Fullerton, J. (2010). Recruitment of hard-to-reach population subgroups via adaptations of the snowball sampling strategy. Nursing \& Health Sciences, 12(3), 369-374. doi: 10.1111/j.1442-2018.2010.00541.x

Salganik, M. J., \& Heckathorn, D. D. (2004). Sampling and estimation in hidden populations using respondent-driven sampling. Sociological Methodology, 34(1), 193-240.

Sam, D. L., \& Berry, J. W. (2006). The Cambridge handbook of acculturation psychology. Cambridge, UK: Cambridge University Press.

Schmitt, A. (2015, May 13). The Oregonian: Run a red light and kill 3 kids? Just a tragic accident [Web log post]. Streetsblog USA. Retrieved from http://usa.streetsblog.org/2015/05/13/the-oregonian-run-a-red-light-and-kill-3-kids-just-a-tragic-accident/

Scholl, N., Mulders, S., \& Drent, R. (2002). Online qualitative market research: Interviewing the world at a fingertip. Qualitative Market Research, 5(3), 210-223.

Schramm, A. J., Rakotonirainy, A., \& Haworth, N. L. (2008). How much does disregard of road rules contribute to bicycle-vehicle collisions? Paper presented at the National Conference of the Australasian College of Road Safety, Queensland, Australia.

Simcoe, L. (2015, January 14). Cyclists rolling through stop signs 'acting rationally.' Metro News, Calgary, Canada. Retrieved from http://www.metronews.ca/

Singh, P., Pandey, A., \& Aggarwal, A. (2007). House-to-house survey vs. snowball technique for capturing maternal deaths in India: A search for a cost-effective method. Indian Journal of Medical Research, 125(4), 550-556.

Smith, C. B. (1997). Casting the net: Surveying an Internet population. Journal of Computer-Mediated Communication, 3(1).

Stradling, S. G., Campbell, M., Allan, I. A., Gorell, R. S. J., Hill, J. P., Winter, M. G., \& Hope, S. (2003). The speeding driver: Who, how and why? Edinburg, Scotland: Transport Research Planning Group.

Streeton, R., Cooke, M., \& Campbell, J. (2004). Researching the researchers: Using a snowballing technique. Nurse researcher, 12(1), 35-46. doi: 10.7748/nr2004.07.12.1.35.c5929

Stromberg, J. (2014, May 9). Why cyclists should be able to roll through stop signs and ride through red lights [Web log post]. Vox. Retrived from http://www.vox.com/2014/5/9/5691098/whycyclists-should-be-able-to-roll-through-stop-signs-and-ride

Subramanian, S. V., Jones, K., \& Duncan, C. (2003). Multilevel methods for public health research. In I. Kawachi \& L. F. Berkman (Eds.), Neighborhoods and Health (pp. 65-111). New York, NY: Oxford University Press. 
Sudman, S., \& Freeman, H. (1988). The use of network sampling for locating the seriously ill. Medical Care, 26(10), 992-999.

Tabnak, F., \& Sun, R. (2000). Need for HIV/AIDS early identification and preventive measures among middle-aged and elderly women. American Journal of Public Health, 90(2), 287-288. doi: 10.2105/Ajph.90.2.287

Thompson, S. K., \& Collins, L. A. (2002). Adaptive sampling in research on risk-related behaviors. Drug and Alcohol Dependence, 68, S57-S67.

Trow, M. (1957). Right-wing radicalism and political intolerance. New York: Arno Press.

Tuckel, P., \& Milczarski, W. (2014). Bike lanes + bike share program = bike safety: An observational study of biking behavior in lower and central manhattan. New York: Hunter College.

Tuckel, P., Milczarski, W., \& Rubin, J. (2014). For many New York City motorists a red light does not mean stop: An observational study of the incidence of red light running in New York City. New York: Hunter College.

Urmson, C. (2015, May 11). The view from the front seat of the Google self-driving car. Backchannel. Retrived from https://backchannel.com/the-view-from-the-front-seat-of-the-google-self-drivingcar-46fc9f3e6088\#.9zqtylxfy

USDOT. (2014). Speeding. In Traffic safety facts. Washington, D.C.: National Highway Traffic Safety Administration.

Valdez, A., \& Kaplan, C. D. (1999). Reducing selection bias in the use of focus groups to investigate hidden populations: The case of Mexican-American gang members from South Texas. Drugs and Society, 14, 209-224.

Valdez, A., Kaplan, C. D., \& Codina, E. (2000). Psychopathy among Mexican American gang members: A comparative study. International Journal of Offender Therapy and Comparative Criminology, 44, 46-58.

Van Meter, K. (1990). Methodological and design issues: Techniques for assessing the representatives of snowball samples. NIDA Research Monograph, 31-43.

Van Selm, M., \& Jankowski, N. W. (2006). Conducting online surveys. Quality and Quantity, 40(3), 435-456. doi: 10.1007/s11135-005-8081-8

Vingilis, E., Seeley, J., Wiesenthal, D. L., Wickens, C. M., Fischer, P., \& Mann, R. E. (2013). Street racing video games and risk-taking driving: An Internet survey of automobile enthusiasts. Accident Analysis and Prevention, 50, 1-7. doi: 10.1016/j.aap.2012.09.022

Vivanco, L. (2013). Reconsidering the bicycle: An anthropological perspective on a new (old) thing. New York: Routledge.

Warren, P., Tomaskovic-Devey, D., Smith, W., Zingraff, M., \& Mason, M. (2006). Racial disparity in police stops. Criminology, 44, 707-738. doi: 10.1111/J.1745-9125.2006.00061.X

Watters, J. K., \& Biernacki, P. (1989). Targeted sampling: Options for the study of hidden populations. Social Problems, 36(4), 416-430. doi: 10.1525/sp.1989.36.4.03a00070

Whitehead, L. (2011). Methodological issues in Internet-mediated research: A randomized comparison of Internet versus mailed questionnaires. Journal of Medical Internet Research, 13(4). doi: 10.2196/jmir.1593

Whyte, W. F. (1955). Street corner society; the social structure of an Italian slum. Enl. 2d ed. Chicago: University of Chicago Press.

Winship, C., \& Mare, R. D. (1992). Models for sample selection bias. Annual Review of Sociology, 18, $327-350$.

Wong, T. (2008). Purposive and snowball sampling in the study of ethnic and mainstream community organizations. Paper presented at the Annual Meeting of the Western Political Science Association, San Diego, CA. 
Wood, J. M., Lacherez, P. F., Marszalek, R. P., \& King, M. J. (2009). Drivers' and cyclists' experiences of sharing the road: Incidents, attitudes and perceptions of visibility. Accident Analysis and Prevention, 41(4), 772-776. doi: 10.1016/j.aap.2009.03.014

Wright, R., \& Decker, S. H. (1997). Armed robbers in action. Boston: Northeastern University Press. Wright, R., Decker, S. H., Redfern, A. K., \& Smith, D. L. (1992). A snowball's chance in hell: Doing fieldwork with active residential burglars. Journal of Research in Crime and Delinquency, 29, $148-161$.

Zavestoski, S., \& Agyeman, J. (2015). Incomplete streets: Processes, practices and possibilities, Routledge equity, justice and the sustainable city series. London; New York: Routledge, Taylor \& Francis Group. 